Acta Zoológica Mexicana (nueva serie), Volumen 37, 1-34.

https://doi.org/10.21829/azm.2021.3712386

http://zoobank.org/urn:Isid:zoobank.org:pub:FF3E3221-B908-49D2-8137-6C66E04D171C

Artículo original

\title{
Descripción y señal acústica de tres nuevas especies del género Conocephalus Thunberg, 1815 (Ensifera: Tettigoniidae)
}

\section{Description and acoustic signal of three new species of the genus Conocephalus Thunberg, 1815 (Ensifera: Tettigoniidae)}

\author{
LIZETH BeRENICE CEDILLO-SALINAS, (D) *LUdivinA BARRIENTOS- \\ LOZANO, (D) *AURORA Y. ROCHA-SÁNCHEZ, DURIEL JESHUA \\ SÁNCHEZ-REYES, DDLFONSO CORREA-SANDOVAL
}

Tecnológico Nacional de México-I. T. Ciudad Victoria-División de Estudios de Posgrado e Investigación. Boulevard Emilio Portes Gil No. 1301. Ciudad Victoria, Tamaulipas, México. C.P. 87010.

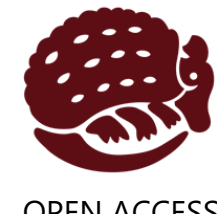

OPEN ACCESS

*Autor corresponsal:

Ludivina Barrientos-Lozano ludivinab@yahoo.com

Aurora Y. Rocha-Sánchez auro_3110@hotmail.com

Cita:

Cedillo-Salinas, L. B., BarrientosLozano, L., Rocha-Sánchez, A. Y., Sánchez-Reyes, U. J., CorreaSandoval, A. (2021) Descripción y señal acústica de tres nuevas especies del género Conocephalus

Thunberg, 1815 (Ensifera: Tettigoniidae). Acta Zoológica Mexicana (nueva serie), 37, 1-34. 10.21829/azm.2021.3712386 elocation-id: e3712386

Recibido: 18 enero 2021 Aceptado: 14 abril 2021 Publicado: 24 mayo 2021
Editor responsable: Magdalena Cruz Rosales

RESUMEN. El género Conocephalus Thunberg, 1815 (Orthoptera: Conocephalinae) está representado por más de 151 especies distribuidas en todo el mundo. Para México se reportan seis especies: Conocephalus (Anisoptera) magdalenae, C. (A.) cinereus, C. (A.) ictus, C. (A.) strictus, C. (A.) resinus y $C$. (Aphauropus) leptopterus. La presencia de especies crípticas en este género dificulta la delimitación de nuevas especies, sin embargo, el uso de caracteres de la genitalia interna y de la señal acústica de llamado son de utilidad para el diagnóstico de nuevos taxones. En este trabajo se describen tres nuevas especies del género Conocephalus: Conocephalus (A.) jaliscienses n. sp., de Lagos de Moreno, Jalisco; C. (A.) tempoalensis n. sp., de Tempoal, Veracruz; y C. (A.) tepemeh $\mathrm{n}$. sp., de San Juan, Huazalingo, Hidalgo. C. (A.) jaliscienses n. sp., presenta afinidad con $C$. (A.) magdalenae; mientras que $C$. (A.) tempoalensis n. sp., y $C$. (A.) tepemeh n. sp., son afines a $C$. (A.) ictus. Las nuevas especies difieren de los taxones con los que muestran afinidad en caracteres morfológicos externos e internos (genitalia), así como en la señal acústica de llamado de los machos. Se ilustran los caracteres de diagnóstico de machos y hembras y se analiza la señal acústica de llamado para cada 
una de las nuevas especies.

Palabras clave: México; biodiversidad; Conocephalinae; morfología; bioacústica

ABSTRACT. The genus Conocephalus Thunberg, 1815 (Orthoptera: Conocephalinae) is made up of c.a 151 species distributed worldwide. Out of these, six species are reported to occur in Mexico: Conocephalus (Anisoptera) magdalenae, C. (A.) cinereus, C. (A.) ictus, C. (A.) strictus, C. (A.) resinus, and $C$. (Aphauropus) leptopterus. The presence of cryptic species within the genus has made it difficult the delimitation of new taxa; however, the use of internal genitalia characters and the acoustic calling signal are useful for the diagnosis of new taxa. In this contribution, three new species of the genus Conocephalus are described: Conocephalus (A.) jaliscienses n. sp., from Lagos de Moreno, Jalisco; C. (A.) tempoalensis n. sp., from Tempoal, Veracruz; and C. (A.) tepemeh n. sp., from San Juan, Huazalingo, Hidalgo. C. (A.) jaliscienses n. sp., shows affinity with $C$. (A.) magdalenae; while $C$. (A.) tempoalensis n. sp. and $C$. (A.) tepemeh n. sp., are related to $C$. (A.) ictus. These new taxa differ from similar species in morphological characters, external and internal (genitalia), as well as in the males' acoustic calling signal. Diagnostic characters of males and females are illustrated, and the acoustic calling signal for each new taxa is analyzed.

Key words: Mexico; biodiversity; Conocephalinae; morphology; bioacoustics

\section{INTRODUCCIÓN}

El género Conocephalus Thunberg, 1815, está representado por aproximadamente 151 especies que se distribuyen en todo el mundo; de éstas, seis especies se presentan en México: Conocephalus (Anisoptera) cinereus Thunberg, 1815; Conocephalus (Anisoptera) ictus (Scudder, 1875); Conocephalus (Anisoptera) magdalenae Naskrecki, 2000; Conocephalus (Anisoptera) resinus (Saussure \& Pictet, 1893-1899); Conocephalus (Anisoptera) strictus (Scudder, 1875); Conocephalus (Aphauropus) leptopterus Rehn \& Hebard, 1915b (Cigliano et al., 2021). Los miembros de este género se caracterizan por presentar tamaño pequeño a mediano (18.0 a $24.5 \mathrm{~mm}$ ), cuerpo estrecho, y generalmente de color verde, a veces marrón; el abdomen es generalmente de color verde o amarillo, con la porción distal de color naranja, rojo o morado; la cabeza y el pronoto con una franja dorsal oscura que se ensancha gradualmente del margen anterior de la cabeza al margen posterior del pronoto; fastigio del vértex comprimido lateralmente y redondeado apicalmente; las antenas filiformes más largas que el cuerpo, ojos pequeños y redondos; pronoto corto, con los lóbulos laterales triangulares; las tegmina pueden estar bien desarrolladas (macrópteras), desarrolladas casi o hasta el final del abdomen (mesópteras), cortas o abreviadas (braquípteras) o escuamípteras (muy cortas, que no rebasan el margen posterior del segundo tergito abdominal); el peine estridulador con dientes en forma de clavija; los cercos generalmente provistos de un diente interno; y las hembras con ovipositor recto o ligeramente curvo, delgado y puntiagudo (Thunberg, 1815; Bolívar, 1877; Naskrecki, 2000). Aunque estos caracteres son de utilidad para separar algunos taxones, la delimitación de especies se dificulta debido a la presencia de especies crípticas. En estos casos, la genitalia interna de los machos y la señal acústica que éstos producen son de utilidad para diagnosticar los taxones por su carácter especie-específico (Walker et al., 2003; Simmons \& García-González, 2011; lorgu, 2012; Wulff \& Lehmann, 2014; 
Chamorro-Rengifo \& Lopes-Andrade, 2014; Barrientos-Lozano et al., 2015; Cedillo-Salinas et al., 2017; lorgu et al., 2017; Dutta et al., 2017; van Haren et al., 2017; Cedillo-Salinas et al., 2019). Adicionalmente, los miembros del género Conocephalus se pueden confundir con miembros del género Orchelimum Serville, 1838-1839, y a la fecha no hay una delimitación clara entre estos dos géneros (Naskrecki, 2000). Rehn y Hebard (1915a; b; c) indican algunos caracteres que pueden ayudar a delimitar estos dos géneros: En Orchelimum el campo estridulatorio de las tegmina del macho es más grande y más ancho, con la porción lateral notablemente más alargada; además, los cercos del macho nunca son fuertes o notoriamente planos distalmente, y el dorso de éstos es en ocasiones carinado e invariablemente excavado en la base del diente medio o cerca de éste; caracteres que no son así en Conocephalus (Rehn \& Hebard, 1915a; b). Por otra parte, el plato subgenital del macho tiene el margen distal casi siempre en forma de " $\mathrm{V}$ " o " $\mathrm{U}$ "; mientras que en miembros del género Conocephalus esta porción es truncada (Rehn \& Hebard, 1915a; c). Morris (2020) menciona que los miembros del género Orchelimum son más grandes y robustos que los de Conocephalus. Otro carácter relevante que puede ayudar a delimitar estos dos géneros es la frecuencia pico del canto de llamado del macho. La frecuencia pico en Orchelimum está en un rango acústico de aproximadamente $18 \mathrm{kHz}$, mientras que en Conocephalus el pico espectral dominante está en el rango ultrasónico de 30 kHz o mayor (Morris \& Walker, 1976; Naskrecki, 2000).

A pesar de la diversidad y riqueza del género Conocephalus, en México se han realizado pocos estudios sobre este grupo, entre los más recientes destacan los siguientes. Naskrecki (2000), en su estudio sobre esperanzas de Costa Rica, reportó la señal acústica de varios taxones del género Conocephalus, cuya distribución se extiende hasta México. Fontana et al. (2013), por su parte, describieron por primera vez al macho de Conocephalus (Aphauropus) leptopterus, en tanto que Barrientos-Lozano et al. (2015) reportaron la variación en la señal acústica en dos poblaciones alopátricas de Conocephalus (A.) ictus. Cedillo-Salinas et al. (2018) estudiaron la señal acústica de C. magdalenae y Cedillo-Salinas et al. (2019) documentaron la variación interespecífica de la genitalia interna en C. ictus, C. magdalenae, C. cinereus y C. strictus.

Durante el periodo 2000-2020 se recolectaron ejemplares de Conocephalinae en varias localidades del territorio mexicano. Muchos de éstos se asignaron al género Conocephalus. Al revisar los caracteres morfológicos de diagnóstico y la señal acústica, se encontró que no corresponden a ninguno de los taxones descritos para el género, por lo que en este trabajo se describen tres nuevas especies del género Conocephalus. Se proporciona información sobre caracteres morfológicos de diagnóstico, la señal acústica de llamado, la ecología y la distribución de estos taxones.

\section{MATERIALES Y MÉTODOS}

Ejemplares adultos de Conocephalus spp. se recolectaron en tres localidades del noreste y centro de México: $3 \hat{\jmath}, 1+$, San Juan, Huazalingo, Hidalgo, 20.XI.2017; 1ठ, 3q우, Tempoal, Veracruz, 23.V.2019; 2へ̂̉, Lagos de Moreno, Jalisco, 13.VI.2019. Estos se transportaron vivos al laboratorio de entomología del Tecnológico Nacional de México-Instituto Tecnológico de Ciudad Victoria (TecNM-ITCV). Machos y hembras se mantuvieron separados, un ejemplar por jaula entomológica 
de $15 \times 15 \times 30 \mathrm{~cm}$, a una temperatura promedio de $30 \pm 1^{\circ} \mathrm{C}$, con el fin de evitar la depredación entre ellos y de mantenerlos sexualmente receptivos, lo que facilita así la grabación de la señal acústica. Como alimento se les proporcionaron hojas de durazno y lechuga fresca cada dos días. Para la determinación se utilizaron claves taxonómicas y recursos en línea (Naskrecki, 2000; Walker, 2019; Cigliano et al., 2021). Se tomaron fotografías de los caracteres de diagnóstico con un microscopio estereoscópico marca MOTIC-SWZ-168 ${ }^{\circledR}$, equipado con cámara digital de $10 \mathrm{mp}$. Los caracteres morfológicos que se consideraron fueron los siguientes: en machos y hembras, fastigio del vértex y fastigio frontal (40X), pronoto en vista dorsal y lateral (20X). En machos, aparato estridulador (40X), peine estridulador (50X), cercos en vista dorsal y lateral (20X), cercos y plato subgenital en vista ventral (20X), genitalia interna (40X); en hembras, plato subgenital (20X), ovipositor (20X) y lóbulo del ovipositor (40X). Las medidas de los caracteres morfológicos ( $\mathrm{mm}$ ) se hicieron con el software MOTIC IMAGES PLUS 2.0. Los caracteres que se midieron fueron los siguientes: longitud del cuerpo, desde el margen anterior del fastigio del vértex al ápice del abdomen; longitud del pronoto, desde el margen anterior hasta el posterior a lo largo de la línea media; ancho del pronoto, porción más amplia del metanoto, en vista dorsal; longitud de las tegmina, desde la unión con el tórax hasta el ápice de la misma, a lo largo de la línea media; longitud del fémur anterior, medio y posterior. Adicionalmente, en hembras se midió el ovipositor, desde el vértice de inserción de la valva dorsal al ápice de la misma, en vista lateral. Para la extracción de genitalia interna de machos y terminología de las estructuras se siguió la metodología de Chamorro-Rengifo y Lopes-Andrade (2014) y Rocha-Sánchez et al. (2016). Los componentes de la genitalia interna que se estudiaron son: vesícula (s) eyaculadora (s) (VEY) y titiladores (TS).

Señal acústica. Se estudió el canto de llamado de machos y se analizó una muestra de aproximadamente 10 min por cada ejemplar grabado. Las señales acústicas se grabaron por la noche a una temperatura de $30 \pm 1^{\circ} \mathrm{C}$ con una computadora portátil y un micrófono ultrasónico ULTRAMIC250K-Dodotronic, con frecuencia de muestreo de $250 \mathrm{kHz}$, rango de frecuencia hasta $125 \mathrm{kHz}$, a una distancia de $1 \mathrm{~m}$. Las grabaciones y análisis de las señales acústicas se realizaron con el programa Cool Edit Pro 2.1 (Syntrillium Software Corporation, Phoenix, Arizona, EE. UU.), resolución 16 bits, tamaño FFT 4096. La terminología utilizada para describir el canto de llamado es la propuesta por Morris y Walker (1976), Buzzetti y Barrientos-Lozano (2011) y BarrientosLozano et al. (2015), en donde se definen los conceptos utilizados en este trabajo, como sigue. Canto de llamado: canto producido por un solo macho, generalmente aislado de otros, para atraer a las hembras. Pulsación: sonido aislado producido generalmente por la estimulación de un solo diente del peine estridulador. Tren de pulsaciones (TP): agrupación de primer orden de más de una pulsación, precedida y seguida de un intervalo de silencio, que dura más que cualquier intervalo entre las pulsaciones. Grupo de tren de pulsaciones (GTP) o Equema: agrupación de pulsaciones de segundo orden que comprende dos o más trenes de pulsación producidos en sucesión. Tren de pulsaciones mayor (TPMa): tren de pulsaciones usualmente de mayor duración e intensidad que en Ensifera se produce generalmente al cerrar las tegmina. Tren de pulsaciones menor (TPMe): tren de pulsaciones usualmente más corto y de menor intensidad. Intervalo de silencio mayor (ISMa): intervalo de silencio que sigue a un Tren de pulsaciones mayor. Fonatoma (= Phonatome, sylablle, phrase, PTG o chirp): sonido producido durante un ciclo individual y completo de apertura y cierre de las tegmina, consiste usualmente de un TPMe (apertura) y uno 
mayor (cierre de las tegmina). Se midió la tasa de repetición de GTP o equemas por minuto (E/min). Las variables medidas se expresan como promedio \pm desviación estándar (DE) y rango.

Depósito de material tipo y paratipos. Colección de Ortópteros, Tecnológico Nacional de México-Instituto Tecnológico de Cd. Victoria (TecNM-ITCV).

\section{RESULTADOS Conocephalus (Anisoptera) jaliscienses n. sp. Barrientos-Lozano \& Cedillo-Salinas (Figuras 1-15) \\ http://zoobank.org/urn:Isid:zoobank.org:act:BA4C7FBC-1183-4E1A-9F10-E0FC2EEBB1E0}

Material examinado. Holotipo $1 \delta^{\lambda}$, México, Jalisco, Lagos de Moreno, 1,942 m s.n.m., $21^{\circ} 21^{\prime}$ 31.37" N, 101 54' 50.23" O, 13.VI.2019, Barrientos-Lozano L. Paratipos. 1 ${ }^{\dagger}$, mismos datos del material tipo. Por el momento, solo se han recolectado machos.

Diagnosis. Macho (Figs. 1-12, 14-15). Conocephalus (Anisoptera) jaliscienses n. sp., es similar a C. magdalenae (Figs. 1, 12 vs. 16, 27), se puede diferenciar de ésta última por los siguientes caracteres: longitud total del cuerpo, $22.6 \mathrm{~mm}$ vs. $22.1 \mathrm{~mm}$ en C. magdalenae; fastigio del vértex en vista frontal, más largo (Figs. 2-3 vs. 17-18), proximalmente más angosto, ensanchándose gradualmente, ápice amplio y semi-redondo. Pronoto (Fig. 4 vs. 19) más largo (5.7 vs. 4.0 mm), sinus humeral (Fig. 5 vs. 20) más desarrollado. Tegmina (Figs. 1, 12 vs. 16, 27) más largas (28.9 vs. $25.1 \mathrm{~mm}$ ) y distalmente más angostas; aparato estridulatorio (Fig. 6 vs. 21) más angosto, peine estridulador (Fig. 7 vs. 22) de mayor longitud, dientes más largos y con menor número de dientes [8.0 mm con 39 dientes vs. 5.8-6.3 mm con 47-54 dientes en C. (A.) magdalenae]. Los cercos (Figs. 8-10 vs. 23-25) son menos robustos que en C. magdalenae, el diente ubicado en el primer tercio proximal, en cada cerco, es más corto y la porción distal es más angosta. El plato subgenital (Fig. 10 vs. 25) es más largo y angosto que en C. magdalenae. Genitalia interna, titiladores más anchos y prominentes (Fig. 11 vs. 26). Conocephalus jaliscienses n. sp., puede también separarse de $C$. magdalenae mediante la señal acústica de llamado que emiten los machos (Figs. 14-15 vs. 28-29). Éstos producen equemas de un solo tren de pulsaciones, generalmente, con una duración promedio de $740 \pm 50 \mathrm{~ms}$ (655-807), con una fi pico de $26-36 \mathrm{kHz}$; mientras que C. magdalenae produce grupos de tren de pulsaciones (GTP) de uno a cinco equemas, predominando uno y dos. Los equemas de un tren de pulsaciones tienen una duración promedio de $435 \pm 51$ ms (367-749) con una fi pico de $20-30 \mathrm{kHz}$.

Descripción del macho (Figs. 1-12). Color general del cuerpo, cuando están vivos, marrón claro, dorso del abdomen color crema, últimos tres segmentos color amarillo dorsalmente (Figs. 1, 12). Fastigio del vértex (Fig. 2) comprimido lateralmente, porción a la altura del escapo constreñida, ápice amplio y redondo. Ojos ovales y prominentes (Figs. 2-3, 5). Dorso con una banda marrón oscuro, desde el fastigio del vértex hasta el margen posterior del pronoto, bordeada a cada lado por una franja color crema; ambas bandas color marrón y franjas laterales color crema, que se ensanchan gradualmente hasta el margen posterior del pronoto (Figs. 2, 4, 12). Pronoto (Fig. 4) subrectangular, más largo que ancho, moderadamente convexo; margen anterior sinuoso, emarginado; margen posterior redondo, emarginado y proyectándose moderadamente hacia el 
aparato estridulatorio, carina media conspicua; lóbulos laterales (Fig. 5) color verde claro en ejemplares vivos, ángulo de la cabeza obtuso y emarginado, ángulo posterior casi recto, borde más fuertemente emarginado, sinus humeral moderadamente desarrollado. Tegmina (Figs. 1, 12) bien desarrolladas (macróptero), en ejemplares vivos color marrón-rojizo que rebasan considerablemente el ápice del fémur posterior. Aparato estridulador (Fig. 6) color marrón oscuro con las venas principales color crema; peine estridulador (Figs. 6-7) más ancho en la porción anal que se adelgaza gradualmente hacia la porción distal, de $8.0 \mathrm{~mm}$ de longitud con 39 dientes.

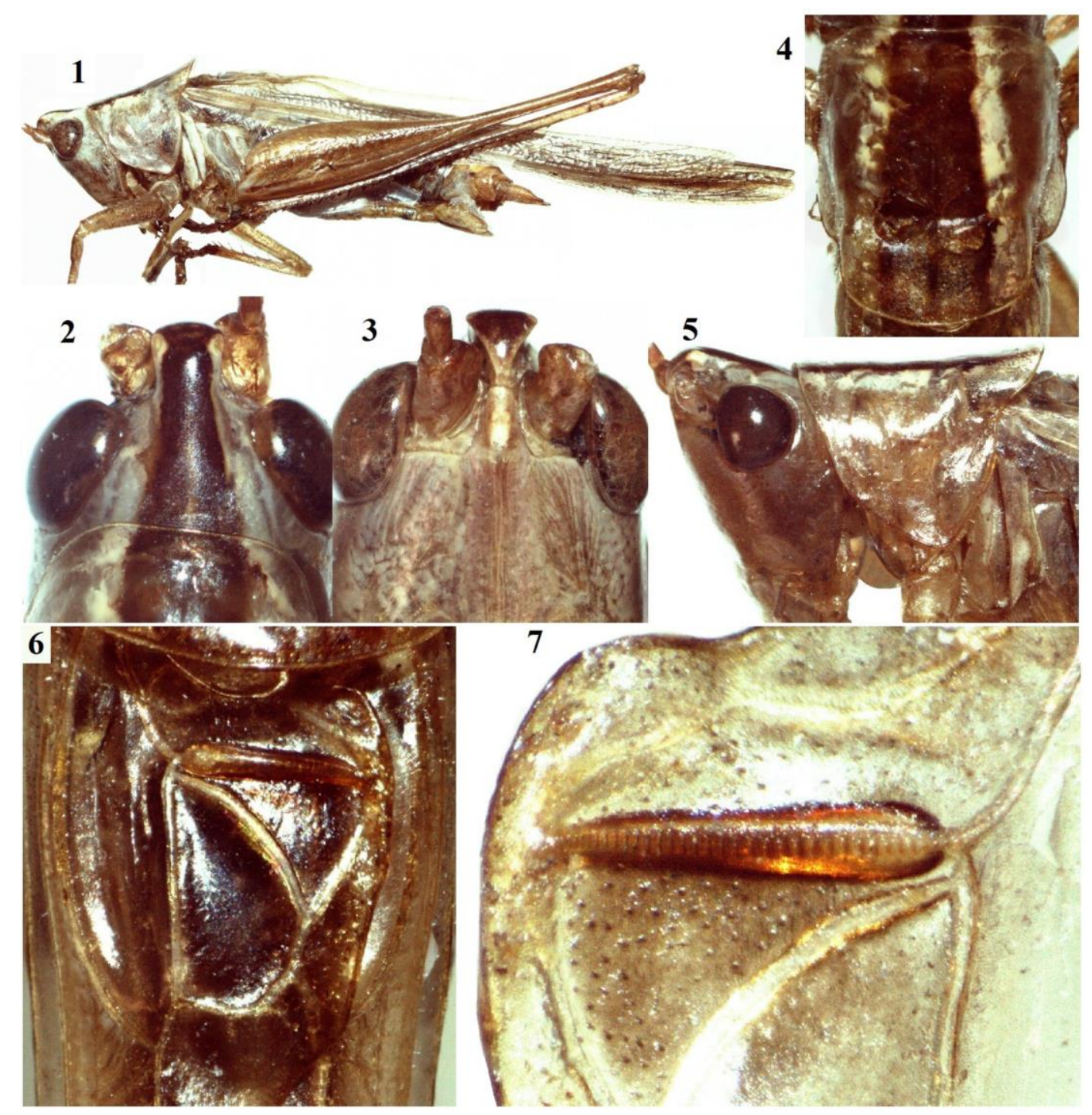

Figuras 1-7. Conocephalus (A.) jaliscienses n. sp. Macho, 1) habitus. 2) cabeza y fastigio del vértex, vista dorsal. 3) cabeza y fastigio del vértex, vista frontal. 4) pronoto, vista dorsal. 5) pronoto, vista lateral. 6) aparato estridulador. 7) peine estridulador.

Cercos (Figs. 8-10) subcilíndricos proximalmente, ensanchados en la porción media aproximadamente, donde se origina - en cada cerco - un diente curvo hacia dentro con una espina distal de color negro, los cercos se adelgazan gradualmente, presentan una protuberancia 
después de la porción media, apicalmente ligeramente comprimidos, el ápice es redondo y divergente. Plato subgenital (Fig. 10) color verde-amarillo claro, cóncavo, sub-hexagonal, distalmente truncado; estilos delgados, largos, divergentes. Genitalia interna, vesículas eyaculadoras y titiladores, como se muestra en la figura 11.

Medidas (mm). Machos. Longitud total del cuerpo, 22.6. Longitud del pronoto, 5.7. Anchura máxima pronoto, 5.0. Longitud de las tegmina, 28.9. Longitud del fémur anterior, 3.9. Longitud del fémur medio, 4.9. Longitud del fémur posterior, 19.9.

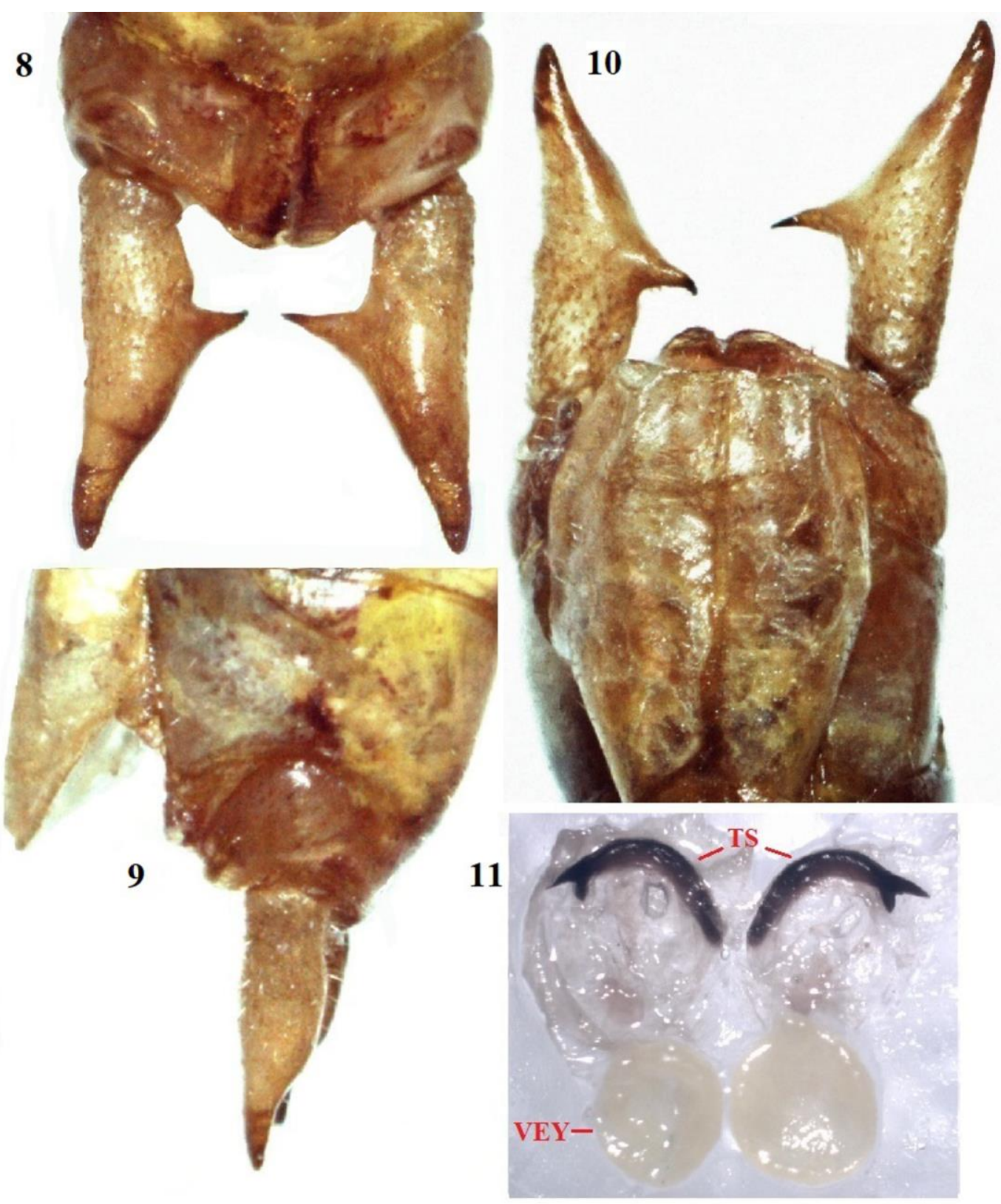

Figuras 8-11. Conocephalus (A.) jaliscienses n. sp. Macho, 8) cercos vista dorsal. 9) cercos vista lateral. 10) plato subgenital, vista ventral. 11) genitalia interna, vesícula eyaculadora (VEY) y titiladores (TS), vista dorsal. 


\section{Hembra. Desconocida}

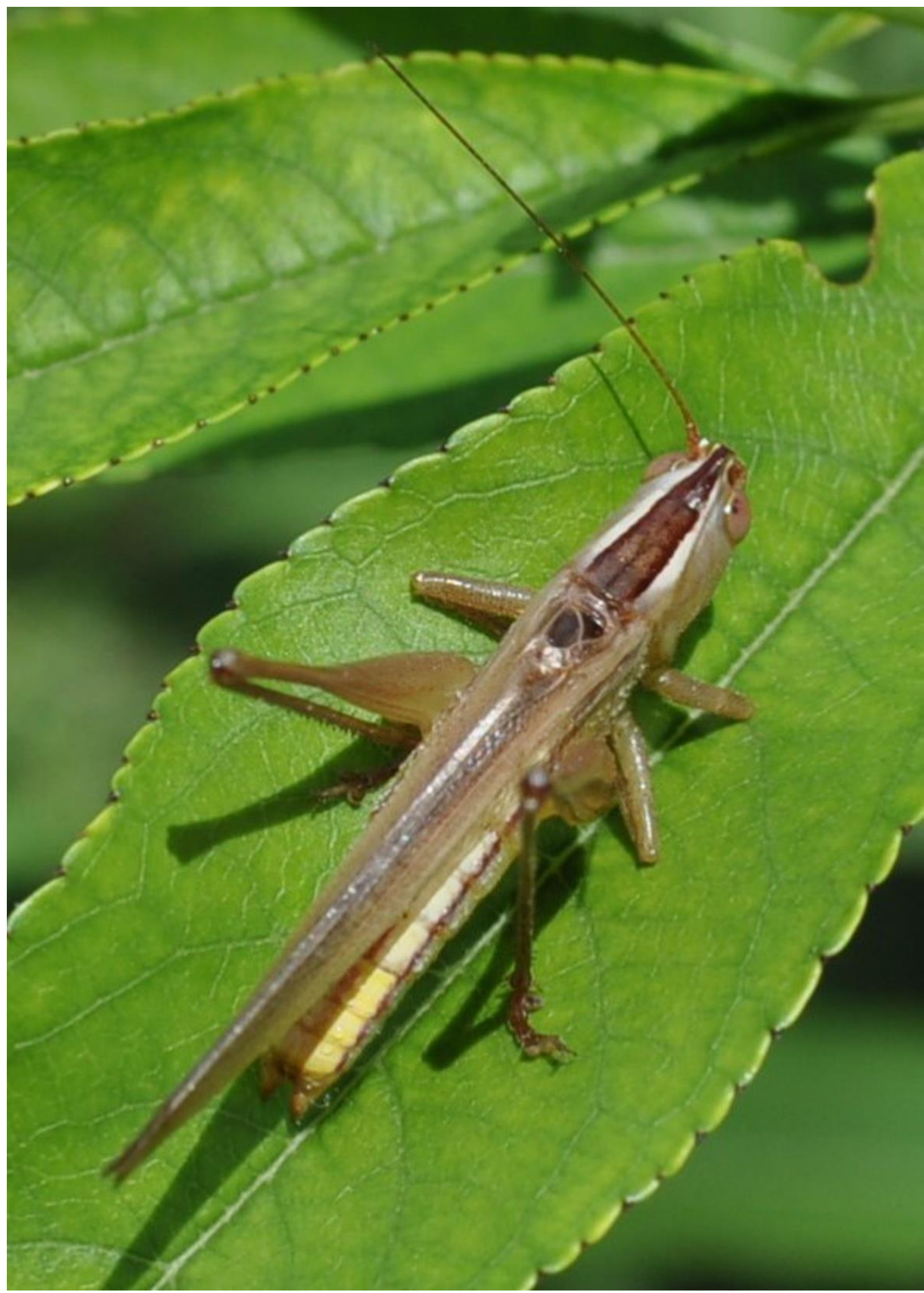

Figura 12. Conocephalus (A.) jaliscienses n. sp. Macho, vivo. Lagos de Moreno, Jalisco, México. 
Distribución (Fig. 13). Solo se ha recolectado en las proximidades de Lagos de Moreno, Jalisco, México, a 1,942 m s.n.m.

Hábitat. Conocephalus (Anisoptera) jaliscienses n. sp., habita en la Provincia Biogeográfica del Eje Volcánico, Subprovincia de los Altos de Jalisco. El clima en el municipio de Lagos de Moreno es de seco a semiseco, con una temperatura media anual de $18.7^{\circ} \mathrm{C}$ y precipitación media anual de $573.2 \mathrm{~mm}$, con lluvias en los meses de junio a octubre. Esta especie vive en pastizales naturales donde predominan las poáceas como Bouteloua spp., Hilaria spp., y Muhlenbergia spp., así como Acacia schaffneri (Fabaceae).

Etimología. El epíteto específico "jaliscienses" se refiere al estado de Jalisco, México, lugar donde se ubica la localidad tipo de esta nueva especie.

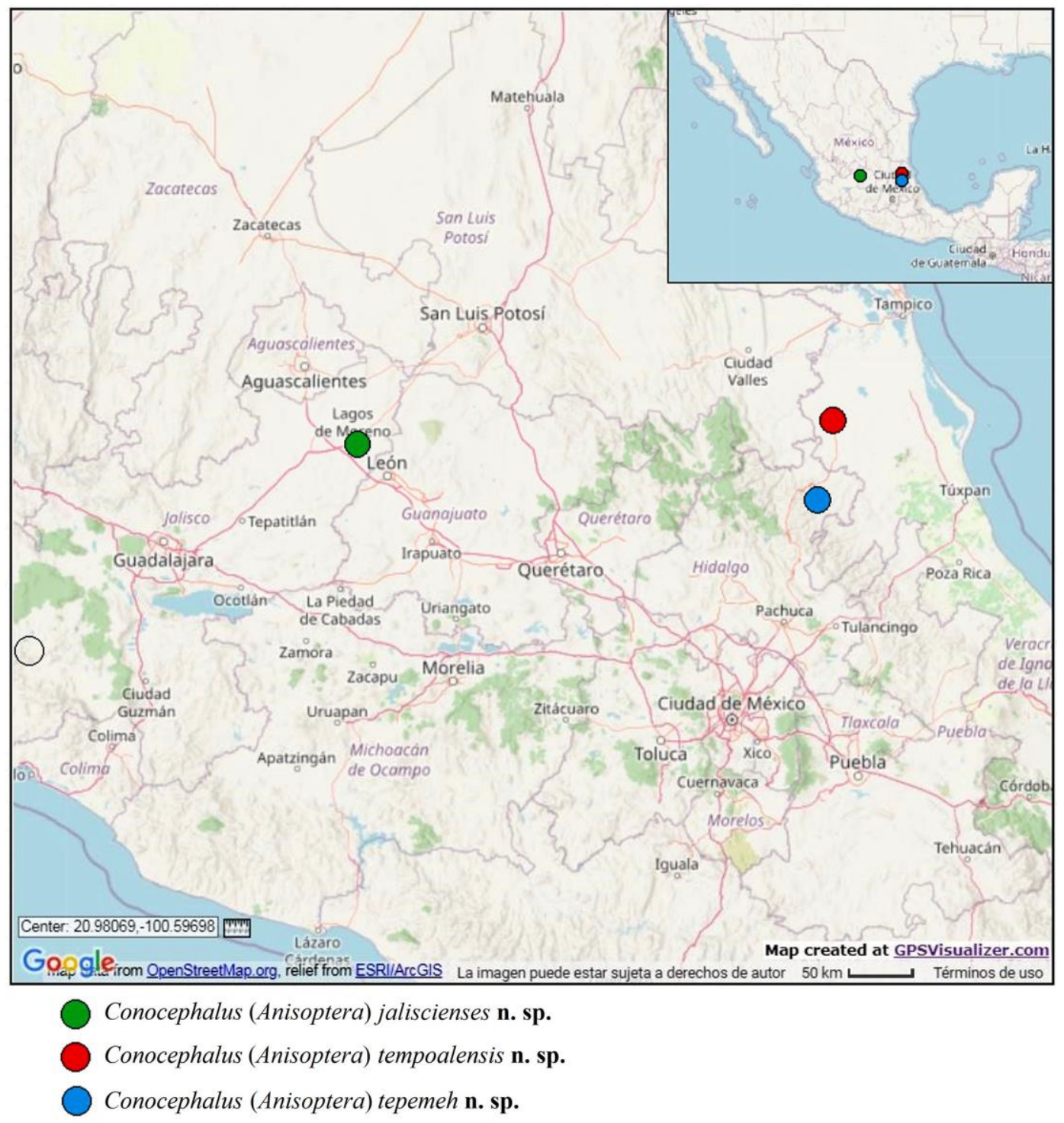

Figura 13. Distribución geográfica. Conocephalus (A.) jaliscienses n. sp., C. tempoalensis n. sp., C. tepemeh n. sp. 
Señal acústica (Figs. 14-15). Se analizaron $10 \mathrm{~min}$ del canto de llamado de C. jaliscienses n. sp. El macho emite la señal acústica en forma continua durante el día y la noche. Ésta se compone de equemas de un tren de pulsaciones, aunque ocasionalmente producen equemas con dos grupos de tren de pulsaciones (2GTP). La tasa de repetición es de $34.0 \pm 3.83$ equemas por $\mathrm{min}(\mathrm{E} / \mathrm{min})$. Los equemas o versos (GTP) están compuestos por una a cuatro sílabas iniciales de menor duración y mayor intensidad, seguidas de un tren de sílabas continuas (35-41 sílabas: $38.4 \pm 1.6$ ). Los equemas de un GTP predominantes tienen una duración de $740 \pm 45$ ms (655-807), se incluyen sílabas iniciales de menor duración y grupo de sílabas continuas. En el tren de sílabas continuas, cada sílaba tiene una duración de $15 \pm 2 \mathrm{~ms}$ (11-18). El intervalo de silencio mayor (ISMa) entre GTP tiene una duración de $803 \pm 67$ ms (720-912). La frecuencia pico (fi) es de $26-36 \mathrm{kHz}$ y el espectro de frecuencia de $16-74 \mathrm{kHz}$, con muy poca liberación de energía después de $74 \mathrm{kHz}$.

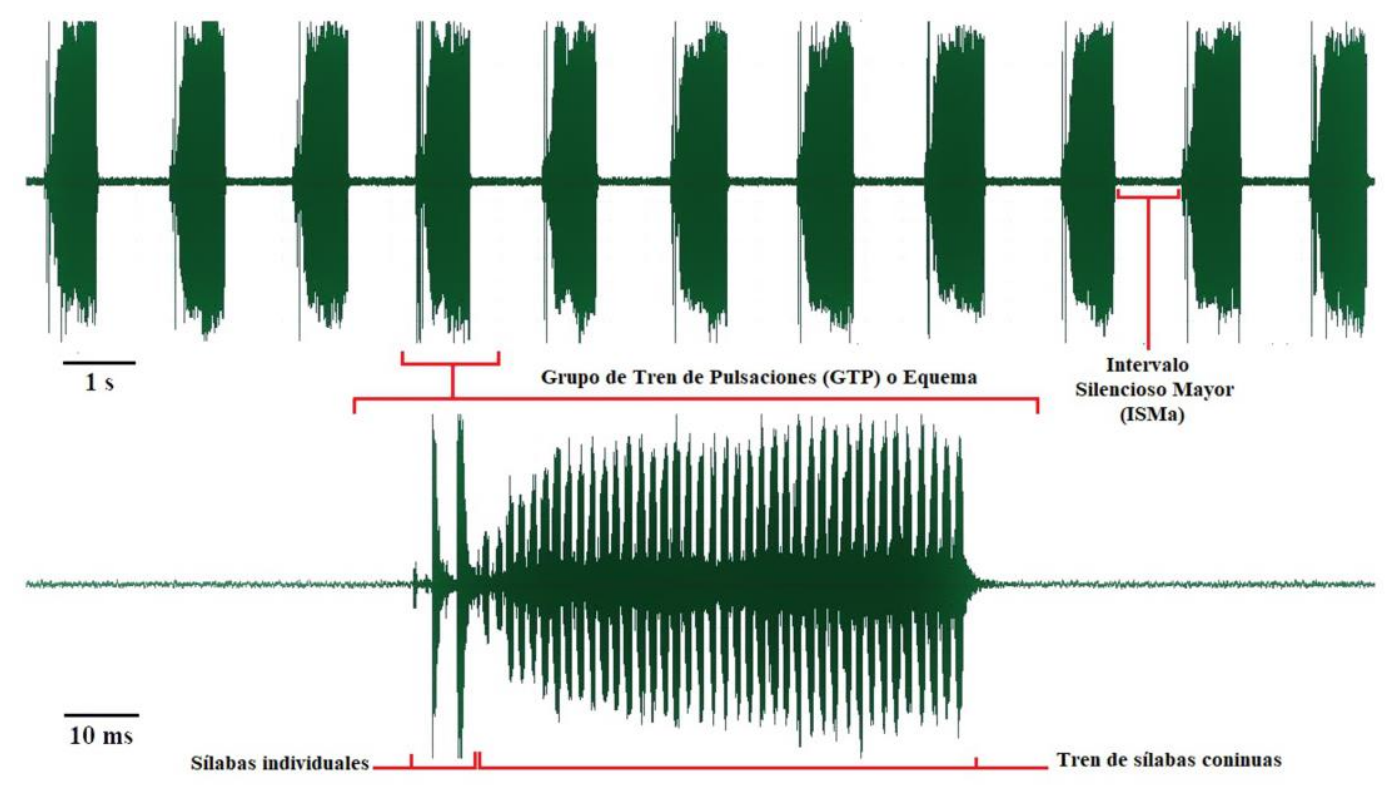

Figura 14. Oscilograma de la señal acústica de llamado de un macho de Conocephalus (A.) jaliscienses n. sp. de Lagos de Moreno, Jalisco, México.

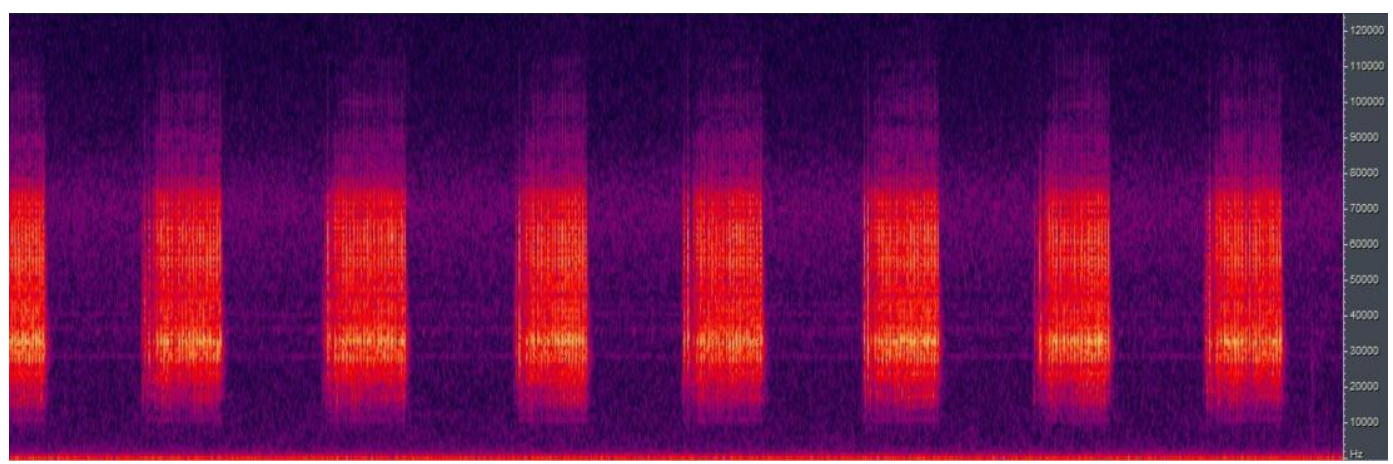

Figura 15. Sonograma y espectro de frecuencia en la señal acústica de llamado de un macho de Conocephalus (A.) jaliscienses n. sp. de Lagos de Moreno, Jalisco, México. 


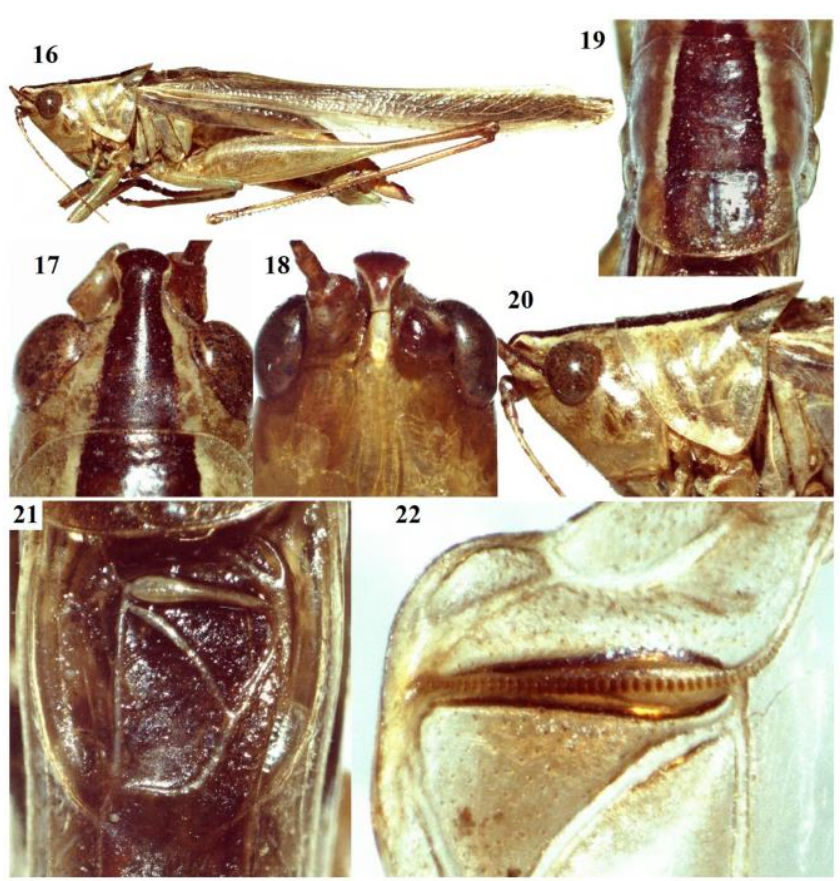

Figuras 16-22. Conocephalus (A.) magdalenae. Macho, 16) habitus. 17) cabeza y fastigio del vértex, vista dorsal. 18) cabeza y fastigio del vértex, vista frontal. 19) pronoto, vista dorsal. 20) pronoto, vista lateral. 21) aparato estridulador. 22) peine estridulador.
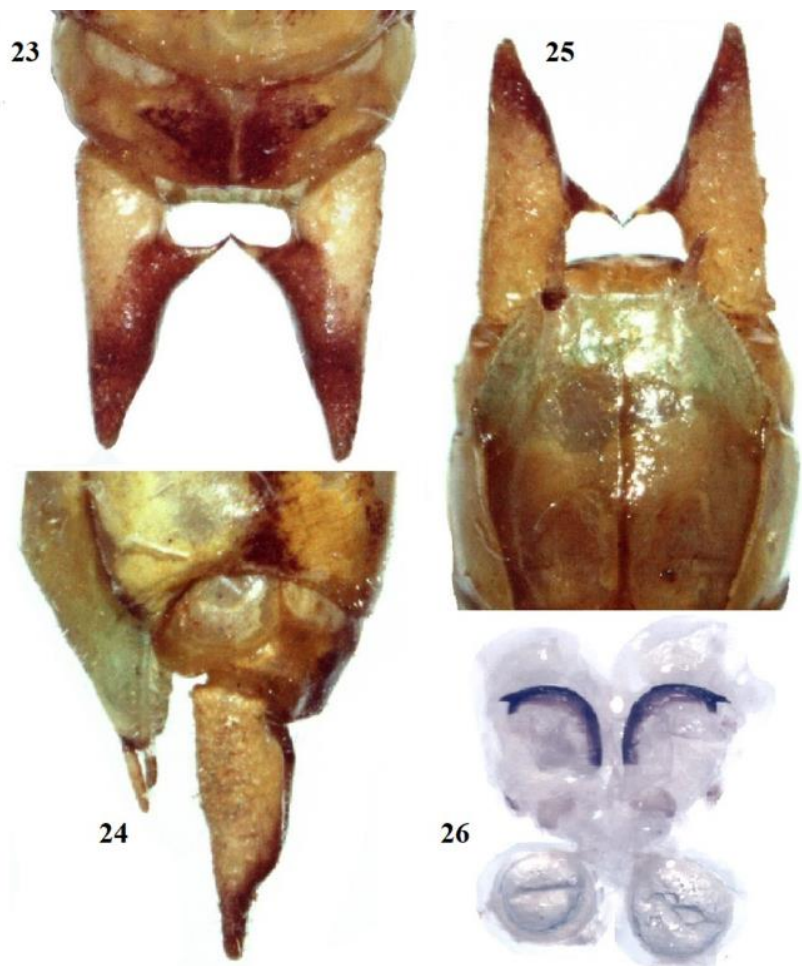

Figuras 23-26. Conocephalus (A.) magdalenae. Macho, 23) cercos vista dorsal. 24) cercos vista lateral. 25) plato subgenital, vista ventral. 26) genitalia interna, vesícula eyaculadora (VEY) y titiladores (TS), vista dorsal. 


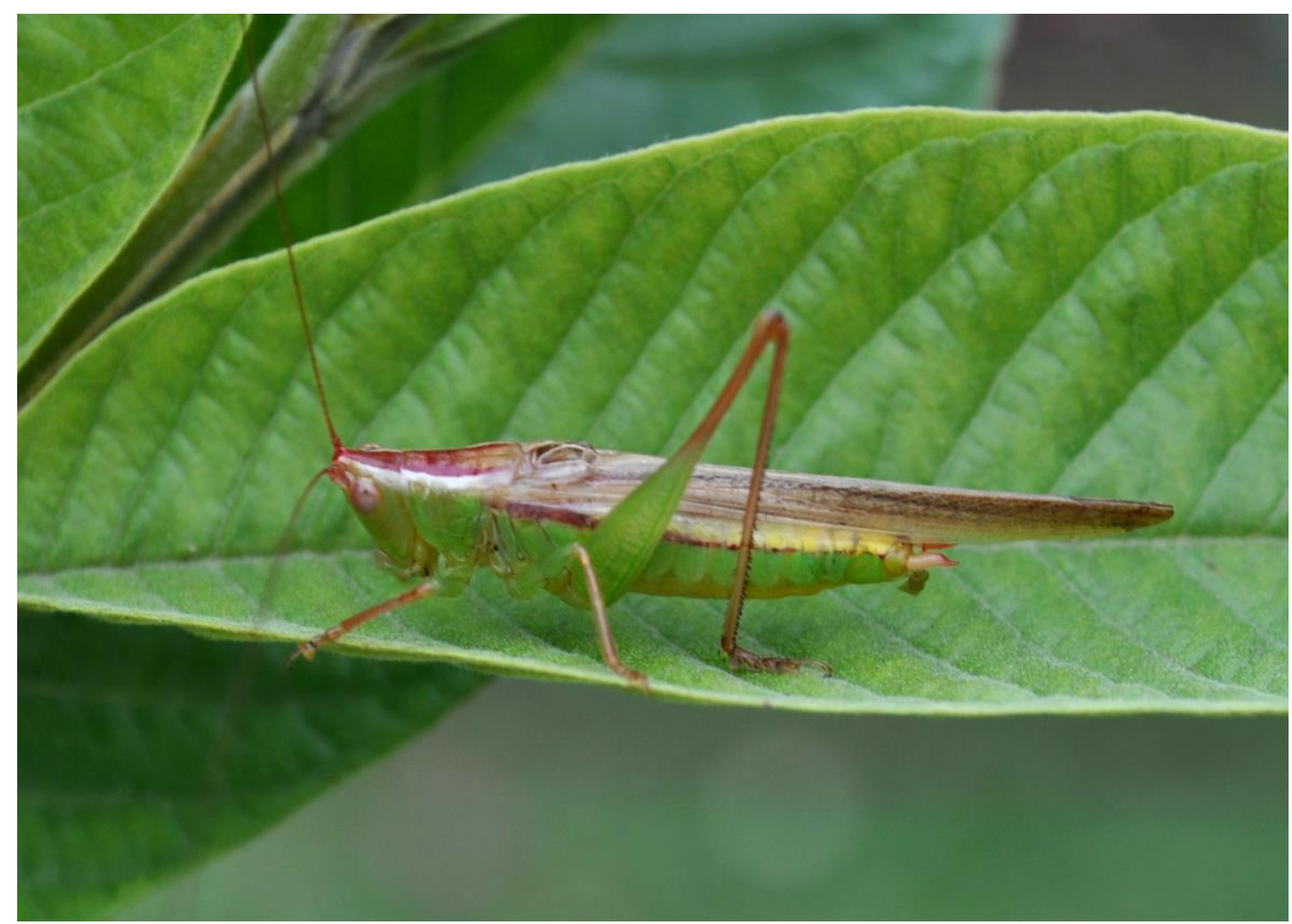

Figura 27. Conocephalus (A.) magdalenae. Macho, vivo. Carretera antigua Cd. Victoria-Jaumave-km 7 , Victoria, Tamaulipas, México.

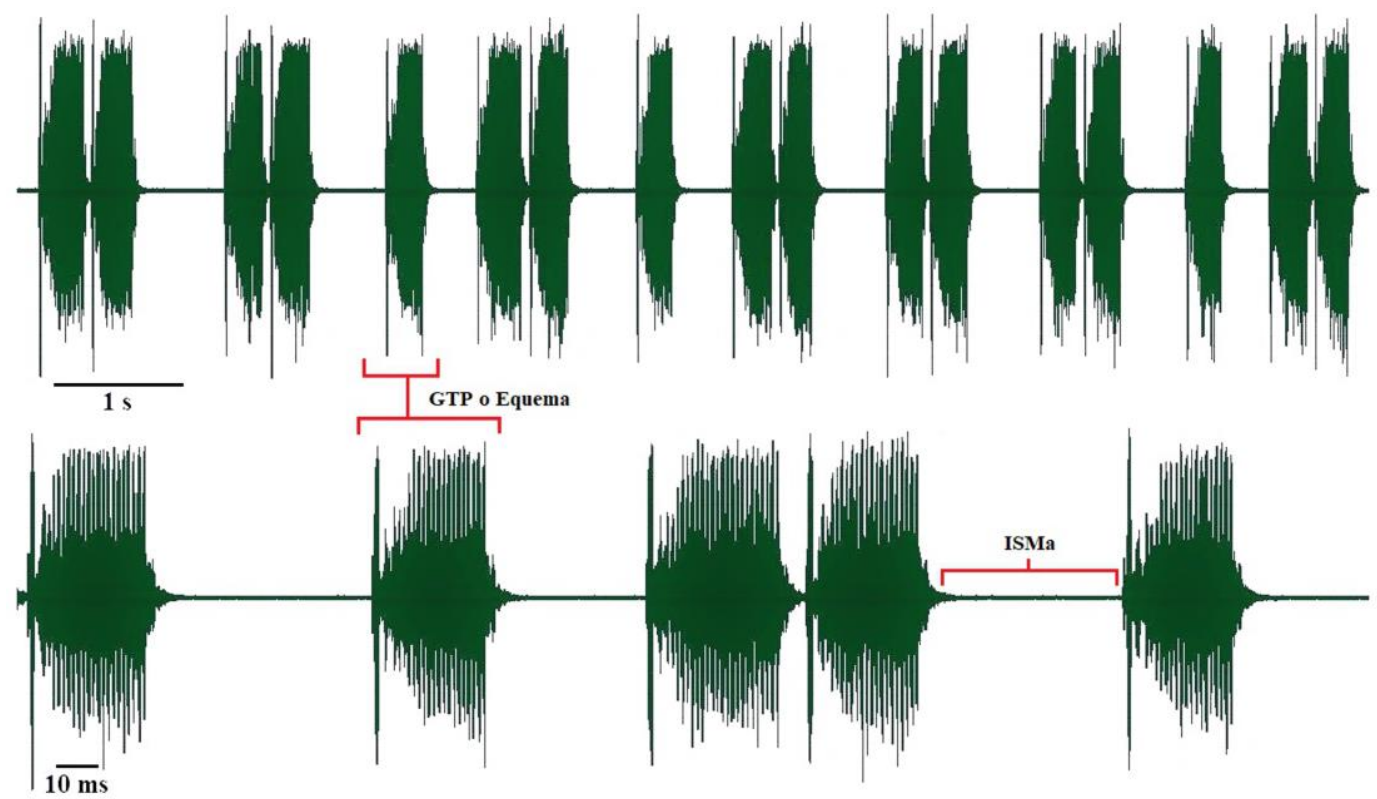

Figura 28. Oscilograma de la señal acústica de llamado de un macho de Conocephalus (A.) magdalenae. Carretera antigua Cd. Victoria-Jaumave-km 7, Victoria, Tamaulipas, México. 


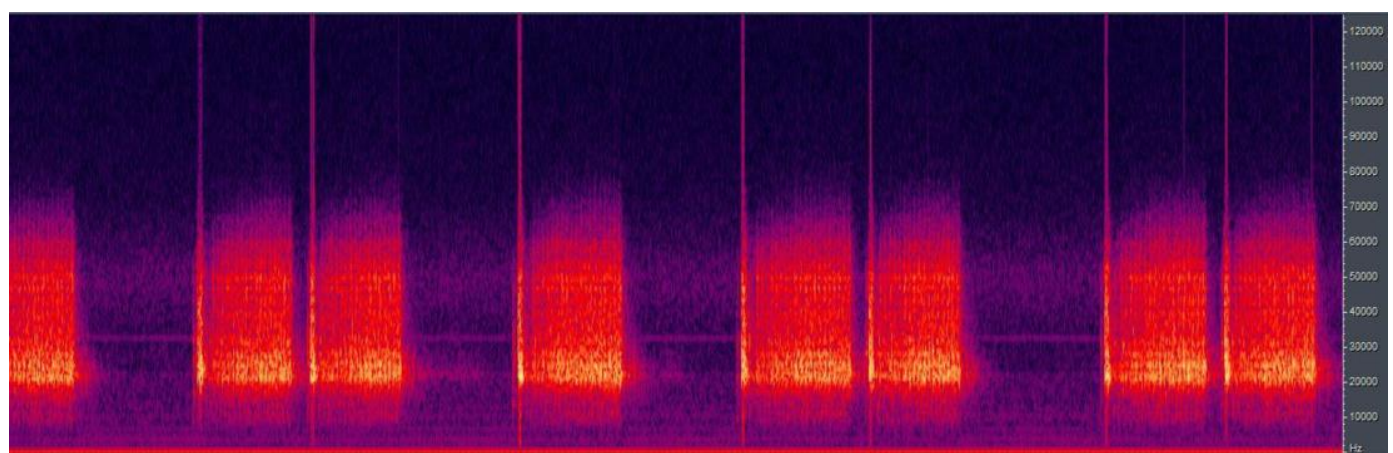

Figura 29. Sonograma y espectro de frecuencia en la señal acústica de llamado de un macho de $C$. magdalenae. Carretera antigua Cd. Victoria-Jaumave-km 7, Victoria, Tamaulipas, México.

\section{Conocephalus (Anisoptera) tempoalensis n. sp. Barrientos-Lozano \& Cedillo-Salinas (Figuras 13, 30-51) \\ http://zoobank.org/urn:Isid:zoobank.org:act:BE077345-C4F6-47B9-B27E-3E9CC955ED5F}

Material tipo. Holotipo 1ð’, México, Veracruz, Tempoal, 50 m s.n.m., $21^{\circ} 31^{\prime} 24.56^{\prime \prime} \mathrm{N}, 98^{\circ} 23^{\prime}$ 17.78" O, 23.V.2019. Barrientos-Lozano L. y colaboradores. Paratipos. $3 q+$, mismos datos del material tipo.

Diagnosis (Figs. 30 -51). Conocephalus (Anisoptera) tempoalensis n. sp. es similar a C. ictus (Figs. 52-74). Se separa de la última especie por los siguientes caracteres: machos ligeramente más grandes, longitud total del cuerpo, $18.2 \mathrm{~mm}$ vs. $18.0 \mathrm{~mm}$ en C. ictus; cabeza (Fig. $31 \mathrm{vs.} \mathrm{53)} \mathrm{globosa}$ y granulosa, fastigio del vértex (Figs. 31-32 vs. 53-54) más corto y robusto. Aparato estridulador (Fig. 35 vs. 57) más grande, vena estriduladora (Figs. 35-36 vs. 57-58) en área anal más amplia, hasta la porción media aproximadamente, en C. ictus disminuye gradualmente a partir del primer cuarto en área anal. El peine estridulador (Fig. 36 vs. 58) de mayor longitud y con dientes más largos y espaciados, $9.0 \mathrm{~mm}$ de longitud con 55 dientes, vs. $5.2 \mathrm{~mm}$ con 65 dientes en C. ictus. Cercos (Figs. 37-39 vs. 59-61) en general más pequeños y menos robustos que en C. ictus. Genitalia interna, titiladores (Fig. 40 vs. 62), más grandes y robustos que en C. ictus. En hembras (Fig. 41 vs. 64), las tegmina son más angostas y el ápice es más agudo, en vista lateral. El plato subgenital (Fig. 46 vs. 69) es distalmente más ancho y truncado, mientras que en C. ictus es más angosto distalmente y la emarginación es más profunda en forma de " $U$ " amplia. El patrón de la señal acústica de C. tempoalensis n. sp., es similar al de C. ictus (Figs. 50-51 vs. 73-74), sin embargo, C. tempoalensis $\mathrm{n}$. sp., produce equemas de mayor duración (7.8 $\pm 2.1 \mathrm{~s} ; 4.7-13.4)$ a una tasa de repetición de $6.6 \pm 1.2$ equemas/min, con una fi pico de $22-34 \mathrm{kHz}$; mientras que en $\mathrm{C}$. ictus la duración de los equemas es de $2.2 \pm 0.74 \mathrm{~s}$ (1.1-3.9) a una tasa de repetición de $25 \pm 7.2 \mathrm{E} / \mathrm{min}$ con una fi pico de $20-30 \mathrm{kHz}$.

Descripción del macho (Figs. 30-40). Color general del cuerpo (Fig. 30) verde claro, porción distal del abdomen color anaranjado, dorsal y ventralmente, incluyendo la genitalia externa. El fastigio del vértex (Fig. 31) es corto y robusto, el ápice redondo; en vista frontal (Fig. 32) la porción que está en contacto con el fastigio frontal es bastante ancha. Dorso con banda marrón oscuro que se extiende desde el fastigio del vértex hasta el margen posterior del pronoto, bordeada por 
franjas delicadas color crema, estas últimas más evidentes en el pronoto (Figs. 31, 33). Pronoto (Figs. 33-34) subcilíndrico, más largo que ancho, margen anterior débilmente sinuoso, margen posterior levantado, proyectándose hacia el aparato estridulatorio; lóbulos laterales (Fig. 34) de color verde claro, emarginados, ángulo cefálico obtuso, posterior subrectangular, sinus humeral poco desarrollado. Tegmina (Fig. 30) cortas que sobrepasan la porción media del abdomen, de color verde-hialinas con área donde se traslapan color marrón-rojizo; aparato estridulador como se muestra en la figura 35, vena estriduladora ancha y globosa en la porción anal, adelgazándose gradualmente desde la porción media hacia el extremo basal; longitud del peine estridulador (Fig. 36) $9.0 \mathrm{~mm}$ con 55 dientes. Cercos (Figs. 37-39) subcilíndricos en la porción proximal, ensanchados medialmente donde se origina el diente que es ancho en la base, moderadamente curvo hacia dentro que se adelgaza gradualmente y termina en una pequeña espina de color marrón; a partir de la porción media, donde se observa una leve protuberancia, los cercos se adelgazan gradualmente, el ápice es amplio y redondo.

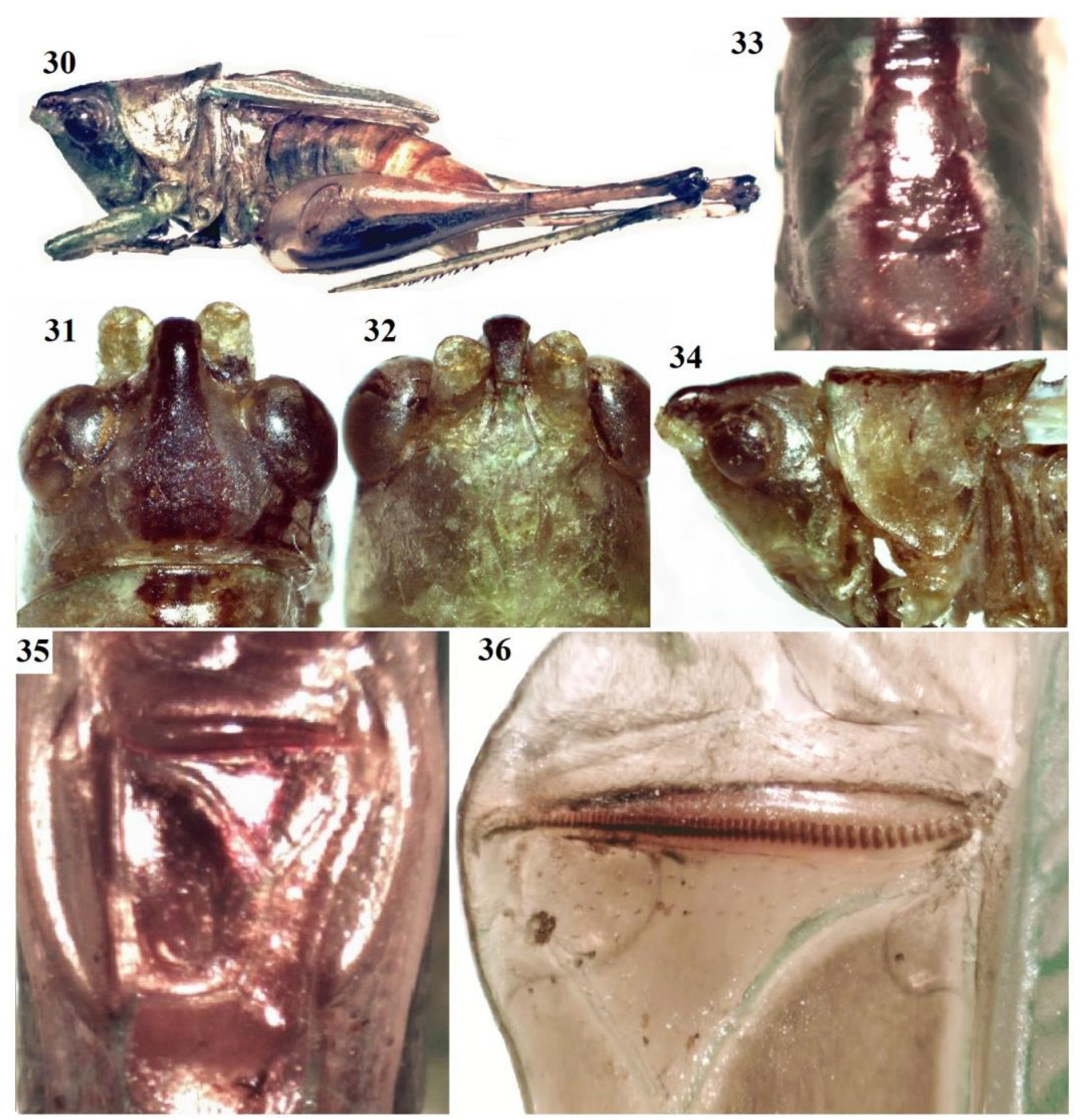

Figuras 30-36. Conocephalus (A.) tempoalensis n. sp. Macho, 30) habitus. 31) cabeza y fastigio del vértex, vista dorsal. 32) cabeza y fastigio del vértex, vista frontal. 33) pronoto, vista dorsal. 34) pronoto, vista lateral. 35) aparato estridulador. 36) peine estridulador. 
Plato subgenital (Fig. 39) cóncavo, distalmente truncado y emarginado; estilos subcónicos, delgados, divergentes. Genitalia interna, vesículas eyaculadoras y titiladores, como se muestran en la figura 40.

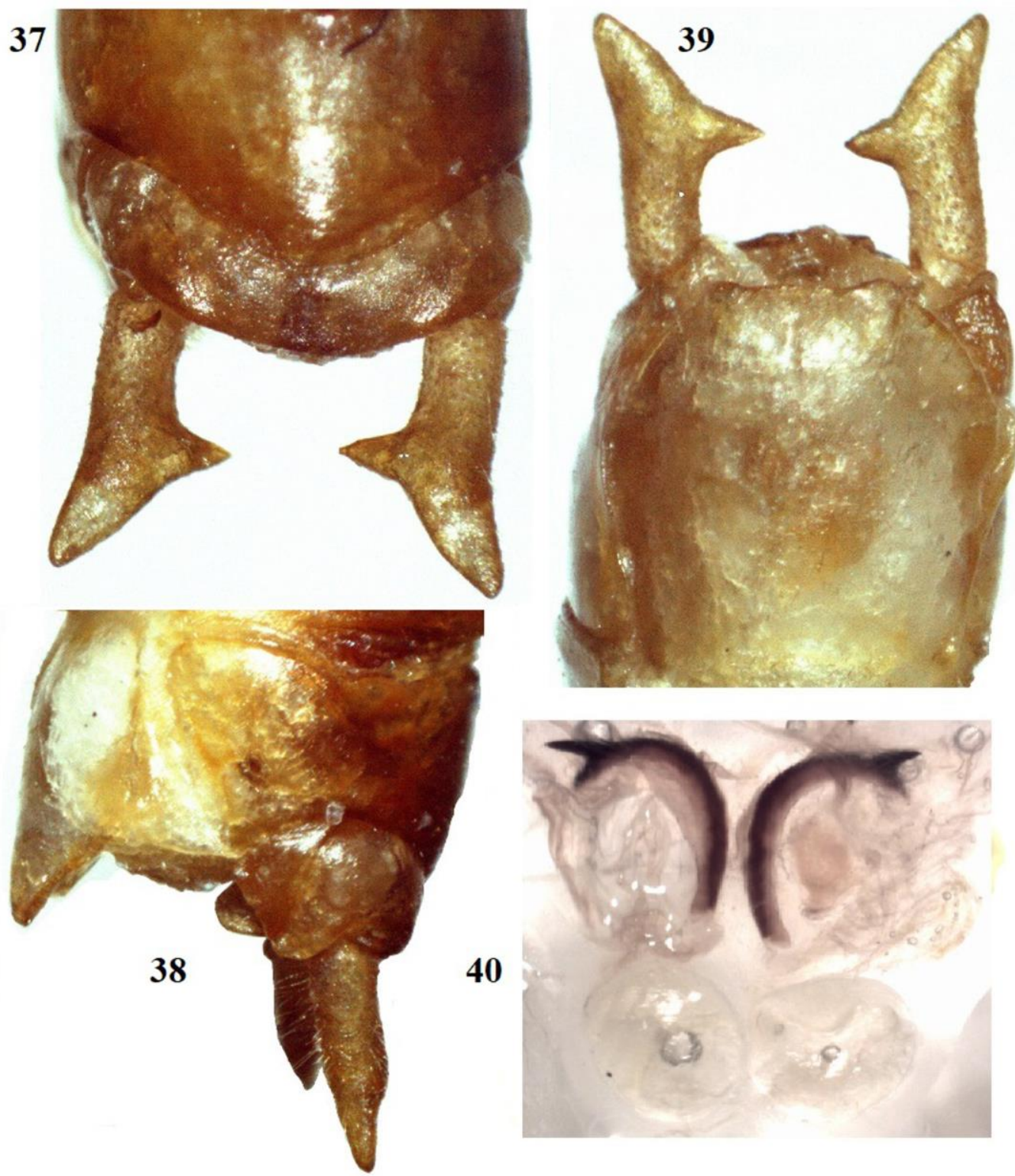

Figuras 37-40. Conocephalus (A.) tempoalensis n. sp. Macho, 37) cercos vista dorsal. 38) cercos vista lateral. 39) plato subgenital, vista ventral. 40) genitalia interna, vesícula eyaculadora (VEY) y titiladores (TS), vista dorsal.

Descripción de la hembra (Figs. 41-49). Similar al macho, ligeramente más robusta (Figs. 41, 49), color general del cuerpo verde claro, dorsalmente color marrón-rojizo. Ojos ovalados y prominentes (Figs. 42-43, 45); sockets y escapo antenales color verde, flagelo color marrón claro. Cabeza y pronoto (Figs. 42,44) con banda color marrón que se extiende desde el fastigio del vértex hasta el margen posterior del pronoto, bordeada por una franja delgada color blanco-crema, esta 
última más conspicua en el pronoto. Tegmina (Figs. 41, 49) color marrón-rojizo, hialinas, que sobrepasan la porción media del abdomen, en vista lateral se ven angostas y con el ápice agudo. Plato subgenital (Figs. 46-47) basalmente ancho, adelgazándose gradualmente hacia la porción distal que es más angosta, truncada y con dos protuberancias color marrón, una a cada lado, y una carina en forma de " $U$ " que le da la apariencia de un escote. Ovipositor (Figs. 41, 48) casi recto, sobrepasa el ápice de los fémures posteriores.
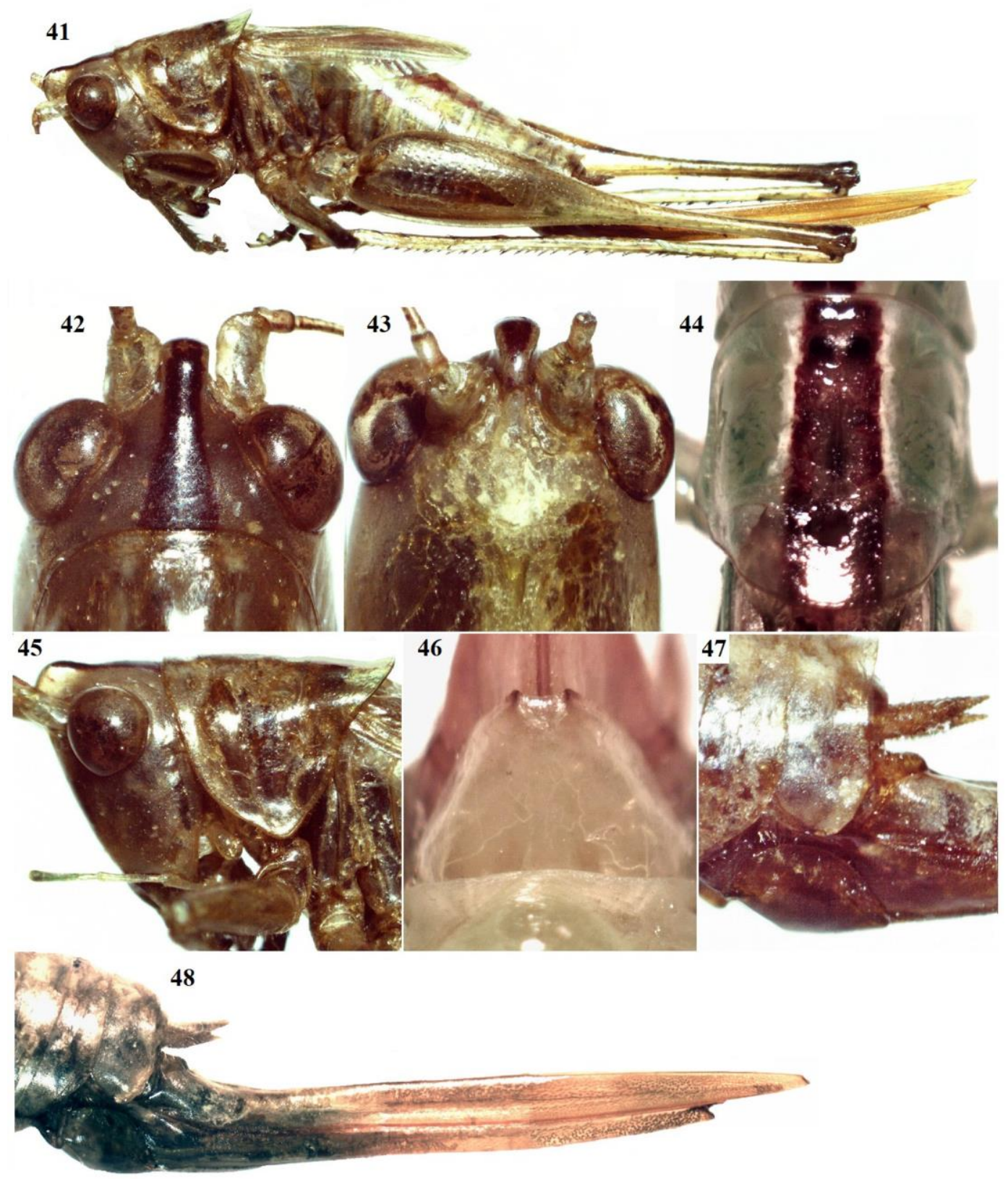

Figuras 41-48. Conocephalus (A.) tempoalensis n. sp. Hembra, 41) habitus. 42) cabeza y fastigio del vértex, vista dorsal. 43) cabeza y fastigio del vértex, vista frontal. 44) pronoto, vista dorsal. 45) pronoto, vista lateral. 46) plato subgenital, vista ventral. 47) plato subgenital, vista lateral. 48) ovipositor, vista lateral. 


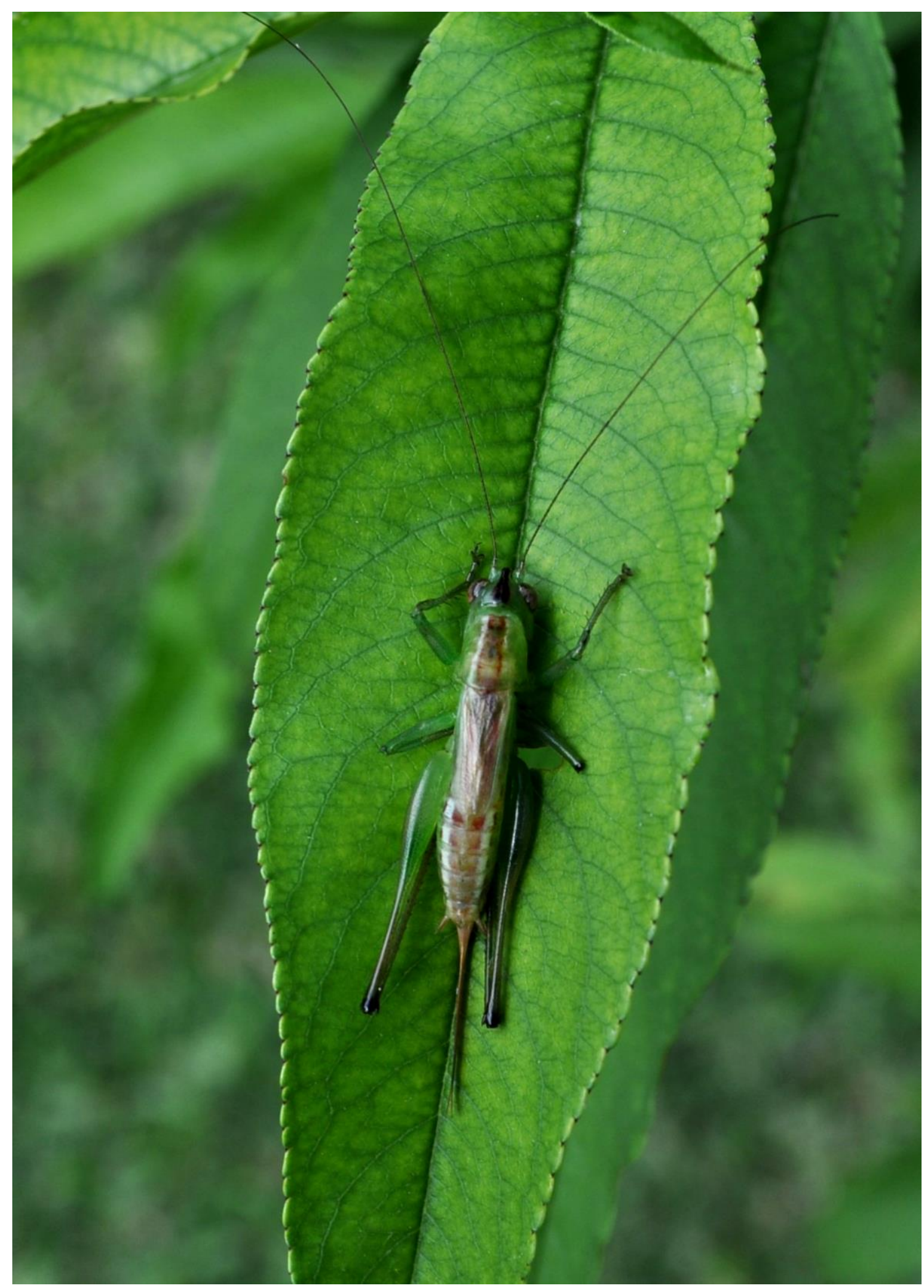

Figura 49. Conocephalus (A.) tempoalensis n. sp. Hembra, viva. Tempoal, Veracruz, México. 
Medidas (mm). Machos. Longitud total del cuerpo, 18.2. Longitud del pronoto, 4.5. Anchura máxima pronoto, 3.9. Longitud de las tegmina, 9.6. Longitud del fémur anterior, 4.3. Longitud del fémur medio, 5.1. Longitud del fémur posterior, 16.3. Hembra. Longitud total del cuerpo, 24.6. Longitud del pronoto, 5.5. Anchura máxima pronoto, 4.0. Longitud de las tegmina, 8.2. Longitud del fémur anterior, 4.9. Longitud del fémur medio, 5.9. Longitud del fémur posterior, 19.0. Longitud total del ovipositor, 12.5 .

Distribución (Fig. 13). Hasta ahora solo se ha recolectado en Tempoal, Veracruz, México a una altitud de $50 \mathrm{~m}$.

Hábitat. Conocephalus (Anisoptera) tempoalensis n. sp., habita en la zona norte del estado de Veracruz, en la región Huasteca. El clima en el municipio de Tempoal es cálido-extremoso, con una temperatura media anual de $24.1^{\circ} \mathrm{C}$ y precipitación media anual de $839 \mathrm{~mm}$. El ecosistema donde vive esta especie está conformado principalmente por vegetación secundaria representada por pastizales dominados por Paspalum spp. y Panicum spp. (Poaceae).

Etimología. El nombre específico "tempoalensis" se refiere a Tempoal, Veracruz, México, localidad tipo de la especie.

Señal acústica (Figs. 50-51). Se analizaron 10 min del canto de llamado de C. tempoalensis n. sp. Éste se produce durante el día y la noche en forma continua. La señal acústica consiste en equemas compuestos de una a seis sílabas iniciales seguidas por un grupo de sílabas continuas (69.4 \pm 20.9 sílabas; 27-131). Las sílabas iniciales son de igual tamaño e intensidad que las sílabas en el grupo de sílabas continuas (duración $84 \pm 6$ ms $(74-95 ; n=30)$. La tasa de repetición es de $6.6 \pm 1.2$ $\mathrm{E} / \mathrm{min}$.

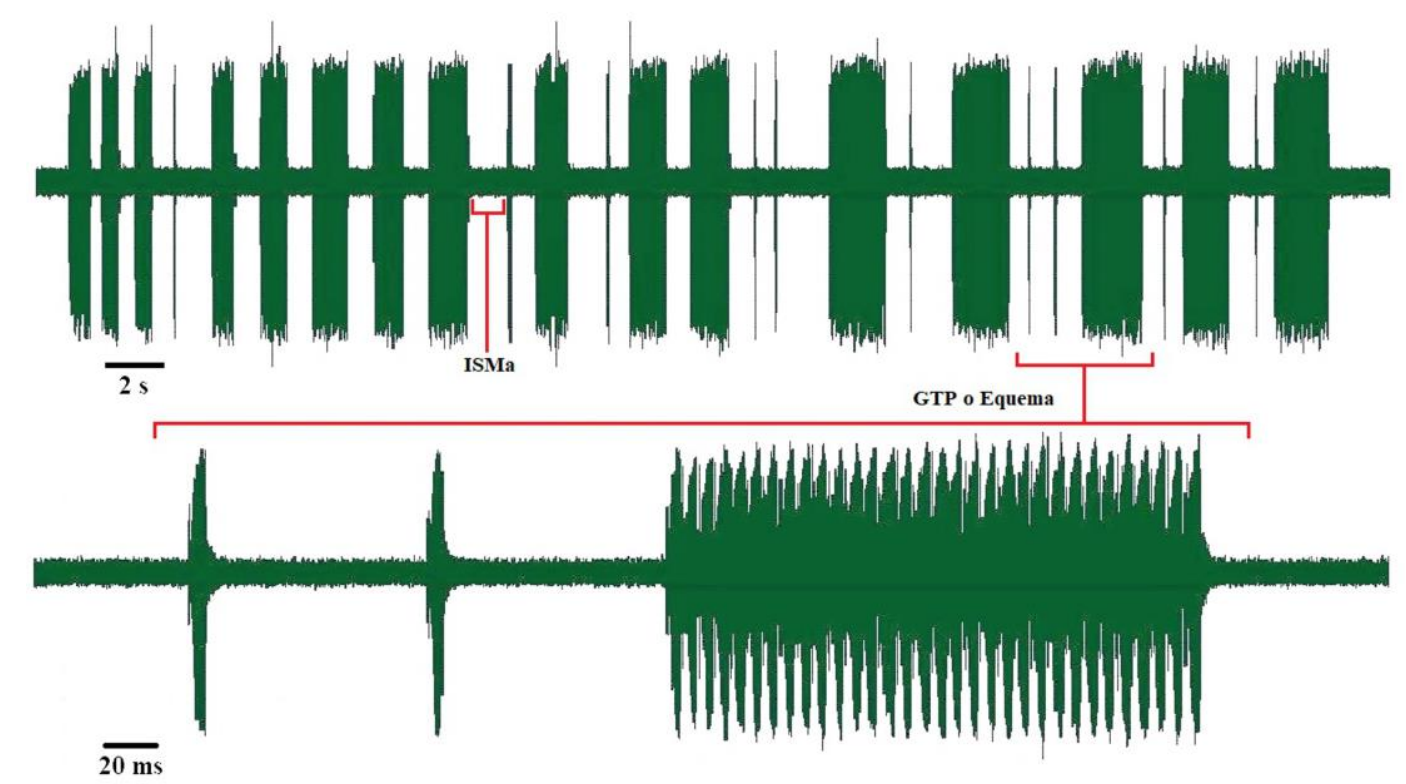

Figura 50. Oscilograma de la señal acústica de llamado de un macho de Conocephalus (A.) tempoalensis n. sp. de Tempoal, Veracruz, México. 
Los equemas o versos tienen una duración de $7.8 \pm 2.1 \mathrm{~s}(4.7-13.4 ; n=20)$, se incluyen sílabas individuales y tren de sílabas continuas. El ISMa entre equemas tiene una duración de 1.8 $\pm 0.5 \mathrm{~s}(0.81-2.65 ; n=20)$. El grupo de sílabas continuas dura $5.7 \pm 1.8 \mathrm{~s}(2.4-11.3 ; n=20)$. El espectro de frecuencia está en el rango de 10 a $60 \mathrm{kHz}$, se libera poca energía después de $60 \mathrm{kHz}$; frecuencia pico $(f i)$ entre $22-34 \mathrm{kHz}$.

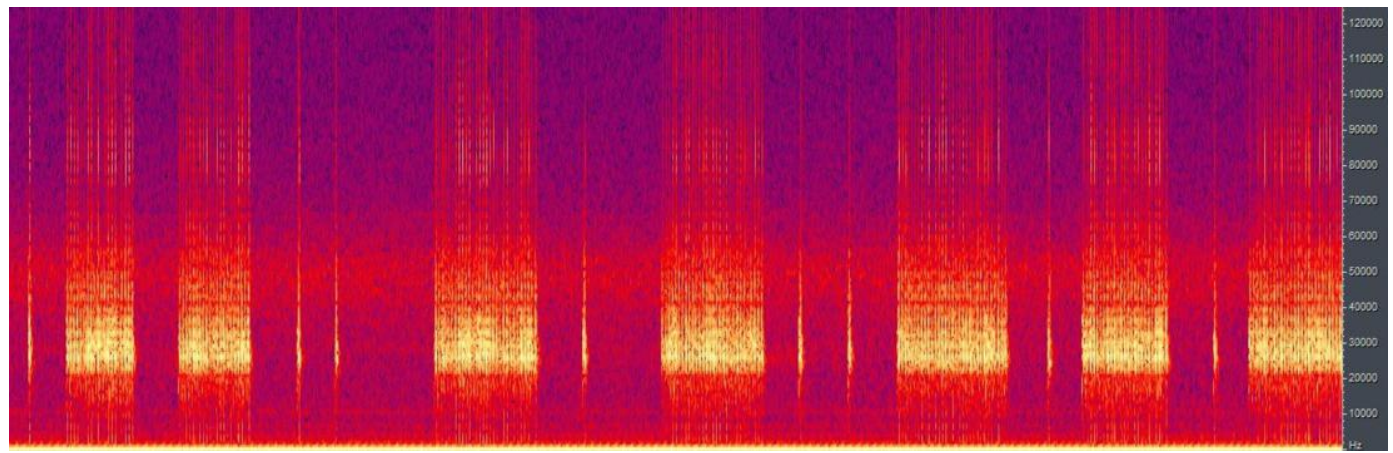

Figura 51. Sonograma y espectro de frecuencia en la señal acústica de llamado de un macho de Conocephalus (A.) tempoalensis n. sp. de Tempoal, Veracruz, México.

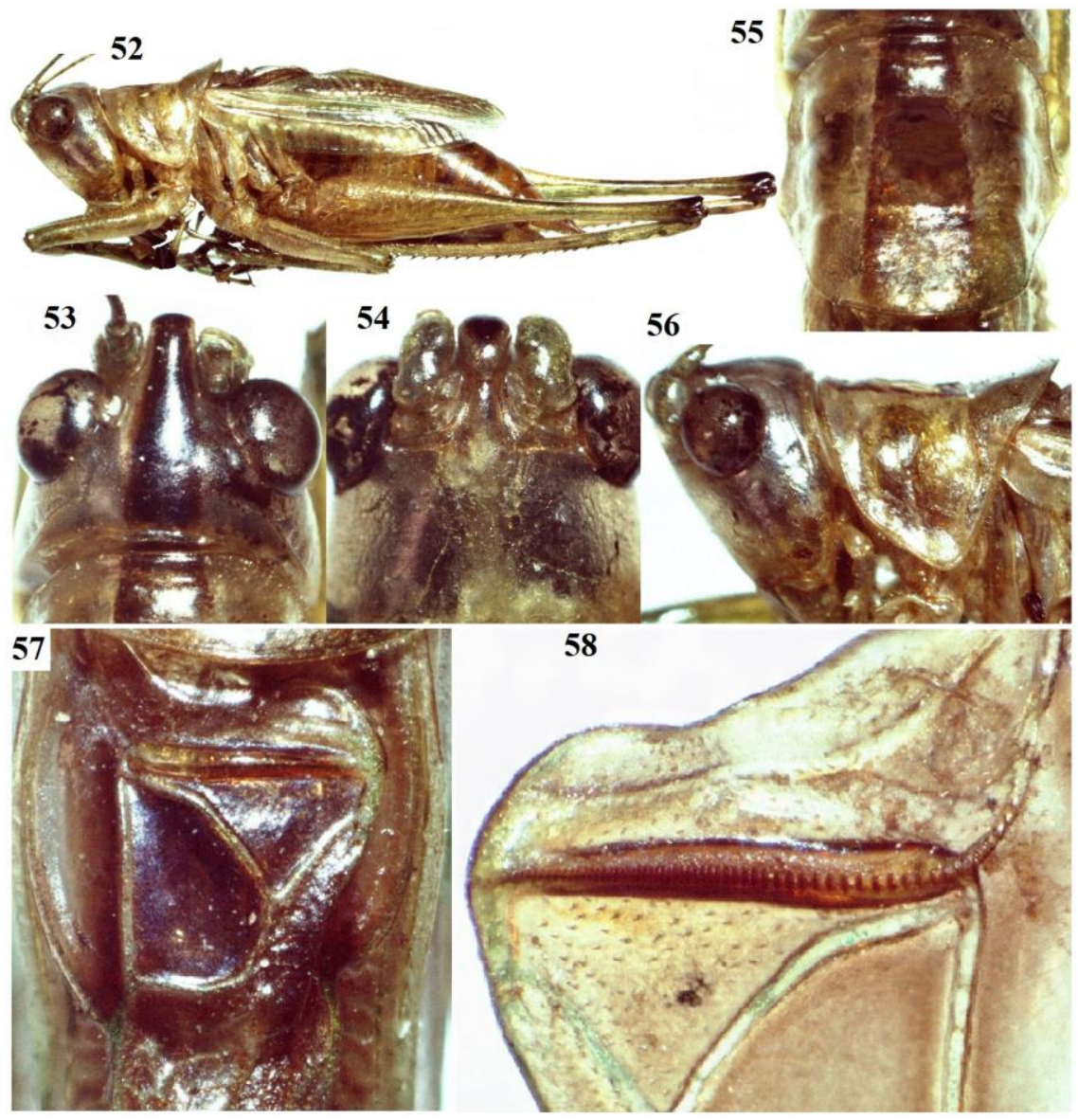

Figuras 52-58. Conocephalus (A.) ictus. Macho, 52) habitus. 53) cabeza y fastigio del vértex, vista dorsal. 54) cabeza y fastigio del vértex, vista frontal. 55) pronoto, vista dorsal. 56) pronoto, vista lateral. 57) aparato estridulador. 58) peine estridulador. 


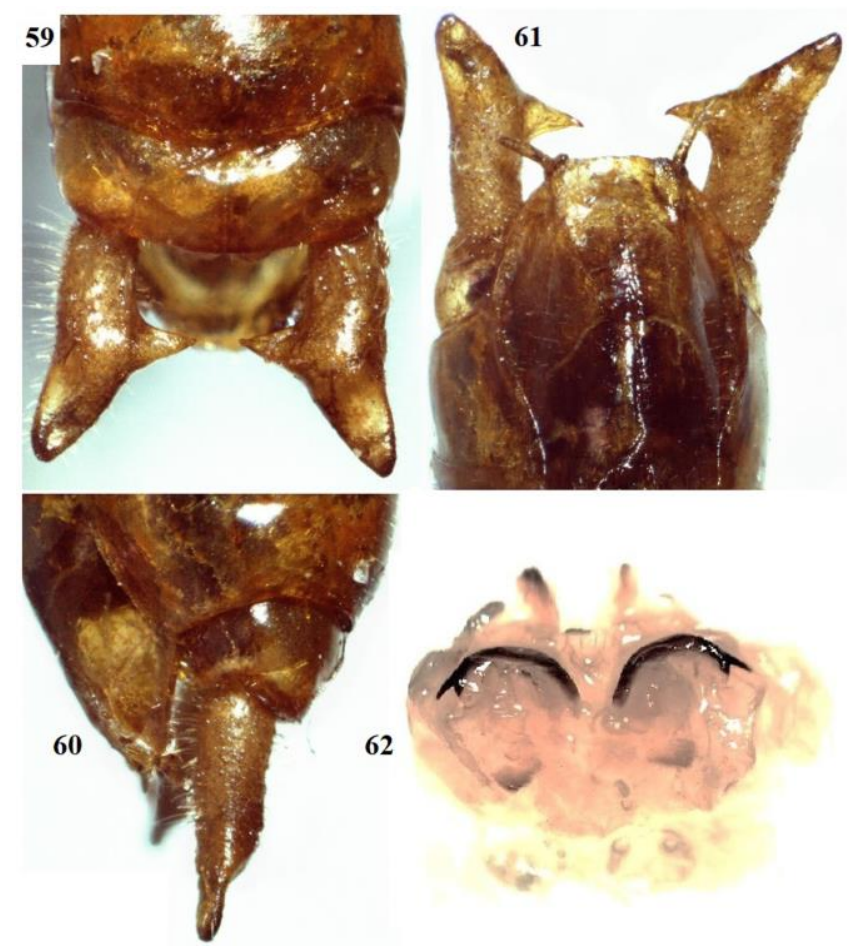

Figuras 59-62. Conocephalus (A.) ictus. Macho, 59) cercos vista dorsal. 60) cercos vista lateral. 61) plato subgenital, vista ventral. 62) genitalia interna, vesícula eyaculadora (VEY) y titiladores (TS), vista dorsal.

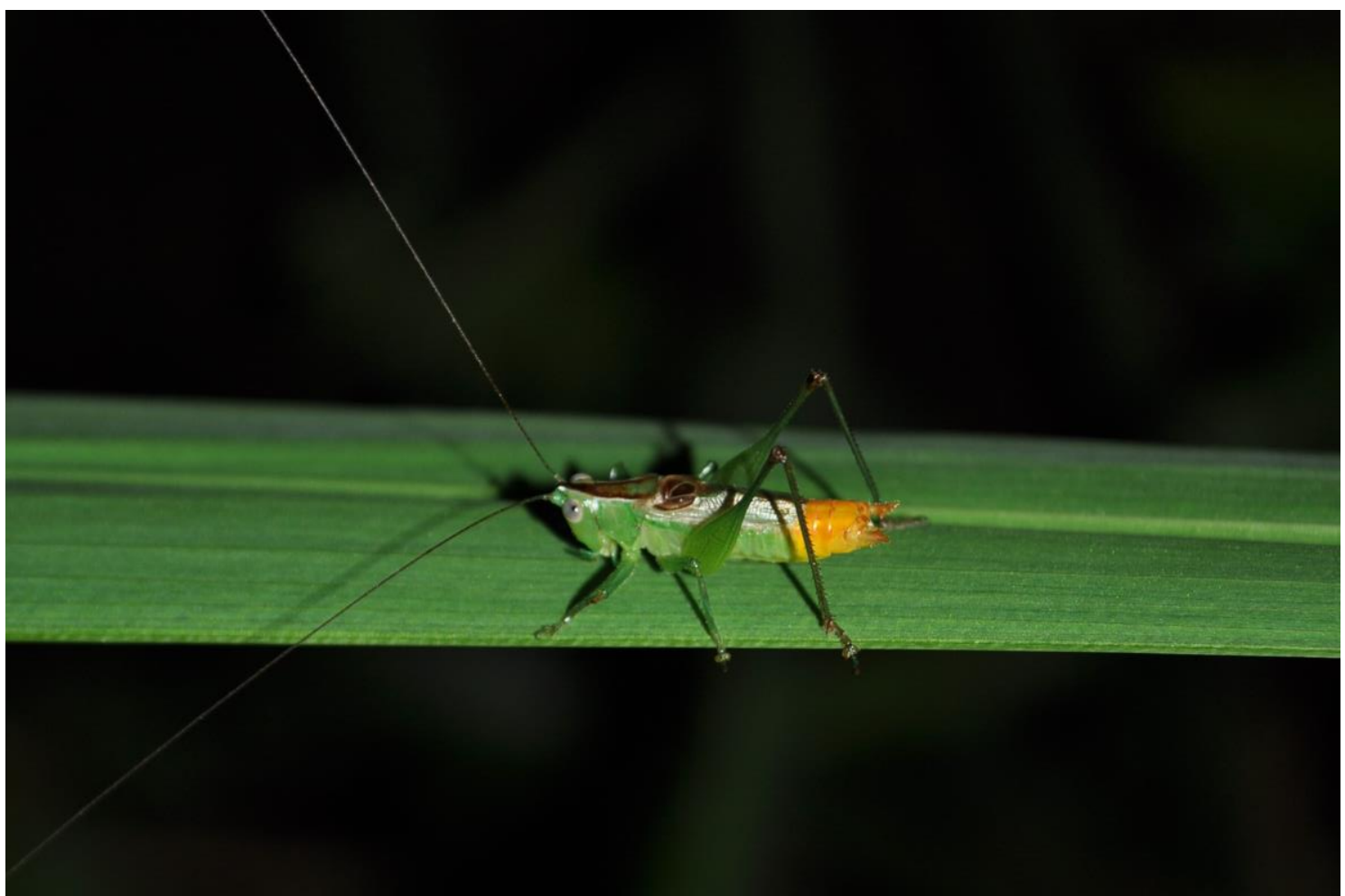

Figura 63. Conocephalus (A.) ictus. Macho, vivo. Reserva de la Biosfera El Cielo, Gómez Farías, Tamaulipas, México. 


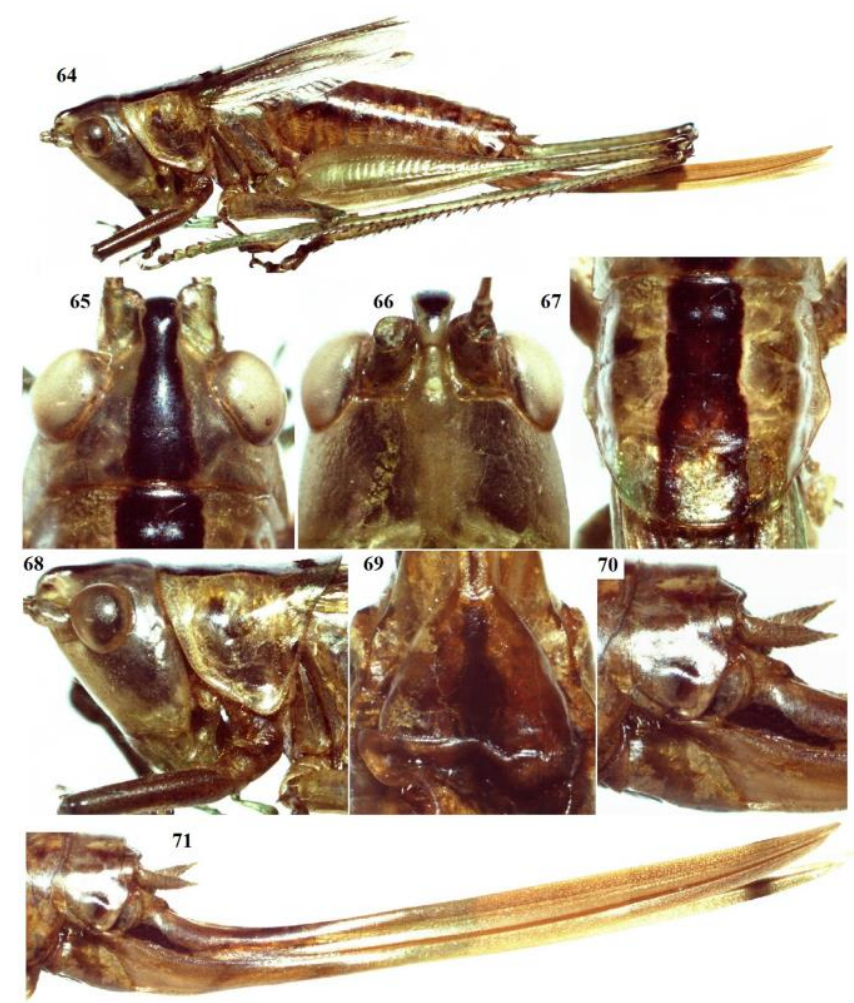

Figuras 64-71. Conocephalus (A.) ictus. Hembra, 64) habitus. 65) cabeza y fastigio del vértex, vista dorsal. 66) cabeza y fastigio del vértex, vista frontal. 67) pronoto, vista dorsal. 68) pronoto, vista lateral. 69) plato subgenital, vista ventral. 70) plato subgenital, vista lateral. 71) ovipositor, vista lateral.

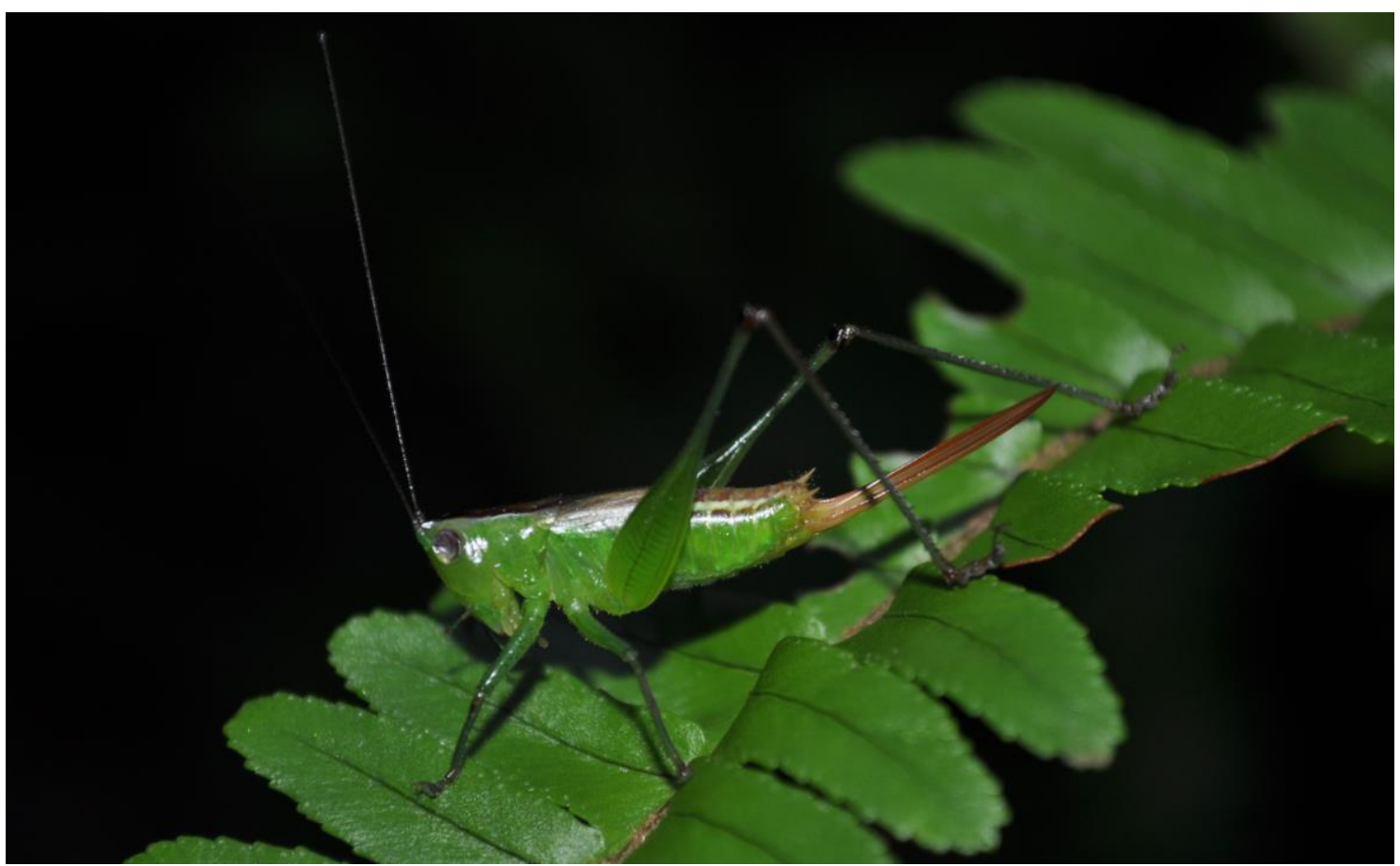

Figura 72. Conocephalus (A.) ictus. Hembra, viva. Reserva de la Biosfera El Cielo, Gómez Farías, Tamaulipas, México. 


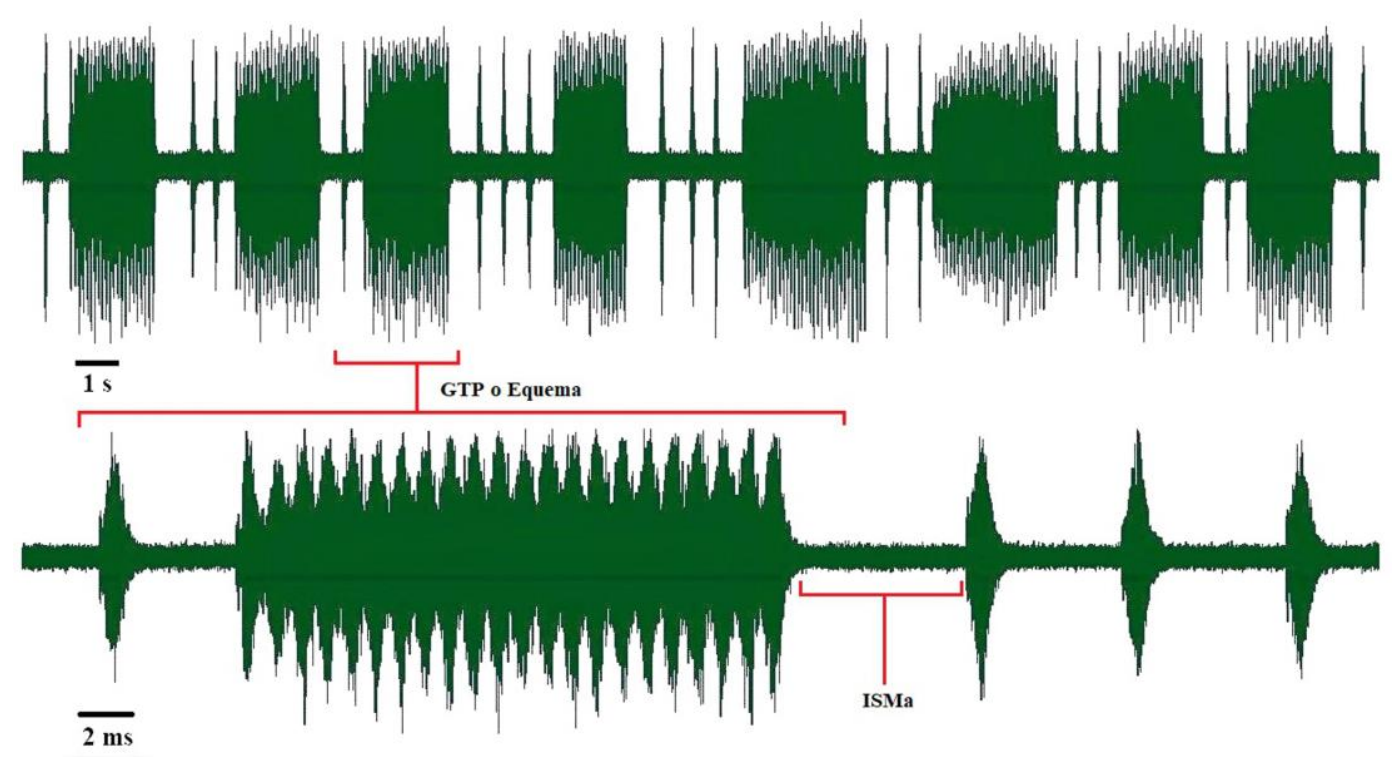

Figura 73. Oscilograma de la señal acústica de llamado de un macho de Conocephalus (A.) ictus de la Reserva de la Biosfera El Cielo, Gómez Farías, Tamaulipas, México.

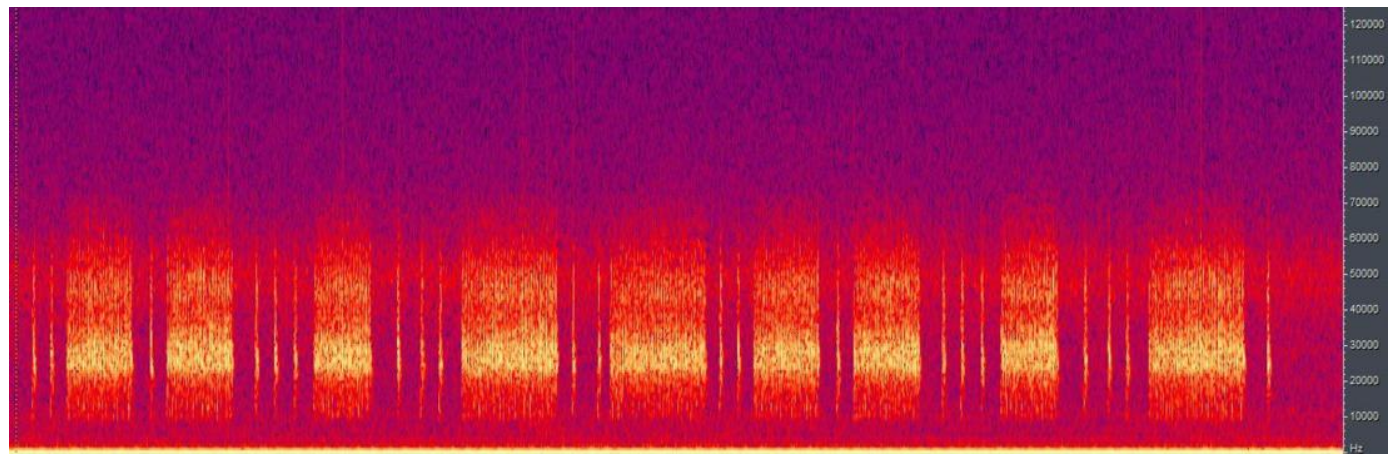

Figura 74. Sonograma y espectro de frecuencia en la señal acústica de llamado de un macho de Conocephalus (A.) ictus de la Reserva de la Biosfera El Cielo, Gómez Farías, Tamaulipas, México.

\section{Conocephalus (Anisoptera) tepemeh n. sp. Barrientos-Lozano \& Cedillo-Salinas \\ (Figuras 13, 75-95) \\ http://zoobank.org/urn:Isid:zoobank.org:act:2DCCEADE-92BE-4C3D-9CCD-565ADCB11087}

Material tipo. Holotipo $1 \partial^{\prime}$, México, Hidalgo, San Juan Huazalingo, 900 m s.n.m., 20 59' 27.6" N, $98^{\circ} 30^{\prime} 16.09^{\prime \prime}$ O, 02.XI.2017. Barrientos-Lozano L. y colaboradores. Paratipos: $2{ }^{\lambda} \sigma^{\lambda}, 1 q$ mismos datos del material tipo.

Diagnosis (Figs. 75-95). Conocephalus (Anisoptera) tepemeh n. sp., es similar a C. ictus (Figs. 5274). Se puede diferenciar de esta última especie por los siguientes caracteres: machos de mayor tamaño, longitud total del cuerpo $21.5 \mathrm{~mm}$ vs. $18.0 \mathrm{~mm}$ en C. ictus; fastigio del vértex (Figs. 76-77 vs. 53-54) más largo y robusto, en vista dorsal y frontal, que en C. ictus. Pronoto (Fig. 78 vs. 55) más largo y oscuro que en C. ictus (6.0 vs. 4.5 mm, respectivamente). Tegmina (Fig. 75 vs. 52) más 
largas, 11.64 vs. $9.8 \mathrm{~mm}$ en C. ictus. Aparato estridulador (Fig. 80 vs. 57) más pequeño, vena estriduladora más ancha y prominente. Peine estridulador (Fig. 81 vs. 58) con dientes más largos y anchos que en C. ictus, longitud $8.1 \mathrm{~mm}$ con 59 dientes vs. $6.2 \mathrm{~mm}$, con 65 dientes aproximadamente en C. ictus. Cercos (Figs. 82-84 vs. 59-61) en general menos robustos y más cortos y la proyección distal más amplia que en C. ictus. Plato subgenital (Fig. 84 vs. 61) con estilos más cortos y separados. Genitalia interna (Fig. 85 vs. 62), titiladores más largos y anchos. En hembras (Fig. 86 vs. 64), las tegmina y el ovipositor son más cortos que en C. ictus (6.4 y 11.2 vs. 7.7 y $13.1 \mathrm{~mm}$, respectivamente). Plato subgenital (Figs. 91-92 vs. 69-70) de mayor tamaño, distalmente truncado, con emarginación menos profunda que en $C$. ictus. El patrón de la señal acústica de C. tepemeh n. sp. es similar al de C. ictus (Fig. 94 vs. 73). No obstante, pueden diferenciarse por la duración de los equemas que es mayor y la tasa de repetición que es menor en C. tepemeh n. sp., con respecto a C. ictus. Conocephalus tepemeh n. sp., produce equemas con una duración de $3.5 \pm 1.0 \mathrm{~s}$ (1.75-5.55), a una tasa de repetición de 5.4 equemas por minuto (E/min); mientras que en $C$. ictus la duración de los equemas es de $2.2 \pm 0.74 \mathrm{~s}(1.1-3.9)$ a una tasa de $25 \pm 7.2 \mathrm{E} / \mathrm{min}$. La duración de equemas incluye sílabas individuales al inicio del equema y tren de sílabas continuas.

Descripción del macho (Figs. 75-85). Color general del cuerpo verde, porción distal-dorsal del abdomen color marrón claro (Fig. 75). Fastigio del vértex (Figs. 76-77) robusto, ápice redondo, en vista dorsal; en vista frontal se observa amplio apicalmente, estrechándose moderadamente entre los sockets antenales. Sockets y escapo antenales de color verde, antenas color marrón claro. Ojos elípticos y prominentes (Figs. 76-77). Dorso con banda marrón oscuro (Figs. 76, 78), que se extiende desde el fastigio del vértex hasta el margen posterior del pronoto, bordeada por franjas delgadas color crema, estas últimas más conspicuas en el pronoto. Pronoto (Fig. 78) subcilíndrico, ligeramente más largo que ancho, margen anterior ondulado y débilmente emarginado, margen posterior emarginado, proyectándose suavemente hacia el aparto estridulatorio; lóbulos laterales (Fig. 79) de color verde claro, subtriangulares, ángulo de la cabeza obtuso, ángulo posterior casi recto; sinus humeral incipiente. Tegmina (Fig. 75) amplias, color verde, dorsalmente color marrón, que sobrepasan la porción media del abdomen; aparato estridulador (Fig. 80) subcircular, color marrón, vena estriduladora amplia y prominente, adelgazándose gradualmente hacia el extremo basal; peine estridulador (Fig. 81) con dientes prominentes y bien separados en área anal, longitud $8.1 \mathrm{~mm}$, con 59 dientes. Cercos (Figs. 82-84) subtriangulares, adelgazándose gradualmente, con una protuberancia globosa en la porción media, distalmente ligeramente comprimidos, ápice redondo; diente interno mediano, robusto, subtriangular, amplio en la base, el ápice termina en una uña color negro, aguda. Plato subgenital (Fig. 84) cóncavo, porción distal truncada y emarginada, estilos delgados, largos, divergentes. Genitalia interna, vesículas eyaculadoras y titiladores, como se muestran en la figura 85.

Descripción de la hembra (Figs. 86-93). Similar al macho, de mayor tamaño (Fig. 86), color general del cuerpo verde, porción distal del abdomen color marrón dorsalmente. Ojos subcirculares y prominentes (Figs. 87-88, 90). Sockets antenales color verde, antenas color marrón. Cabeza y pronoto con banda color marrón oscuro que se extiende a lo largo del fastigio del vértex hasta el margen posterior del pronoto, bordeada por una franja delgada y tenue color blancocrema (Figs. 87, 89). Tegmina (Fig. 86) color verde, dorsalmente con matices marrón-rojizo que 
sobrepasan la mitad del abdomen, en vista lateral el ápice es agudo. Plato subgenital subtriangular, basalmente ancho, ápice angosto, truncado y emarginado (Figs. 91-92). Ovipositor color marrón, en forma de sable (Fig. 93).

Medidas (mm). Machos. Longitud total del cuerpo, 21.5. Longitud del pronoto, 6.0. Anchura máxima pronoto, 4.5. Longitud de las tegmina, 11.6. Longitud del fémur anterior, 4.9. Longitud del fémur medio, 5.4. Longitud del fémur posterior, 18.2. Hembras. Longitud total del cuerpo, 21.6. Longitud del pronoto, 6.0. Anchura máxima pronoto, 4.0. Longitud de las tegmina, 8.1. Longitud del fémur anterior, no disponible (ND). Longitud del fémur medio, ND. Longitud del fémur posterior, 18.3. Longitud total del ovipositor, 11.2 .

Distribución (Fig. 13). Hasta ahora solo recolectado en San Juan, Huazalingo, Hidalgo, México a una altitud de $645 \mathrm{~m}$.

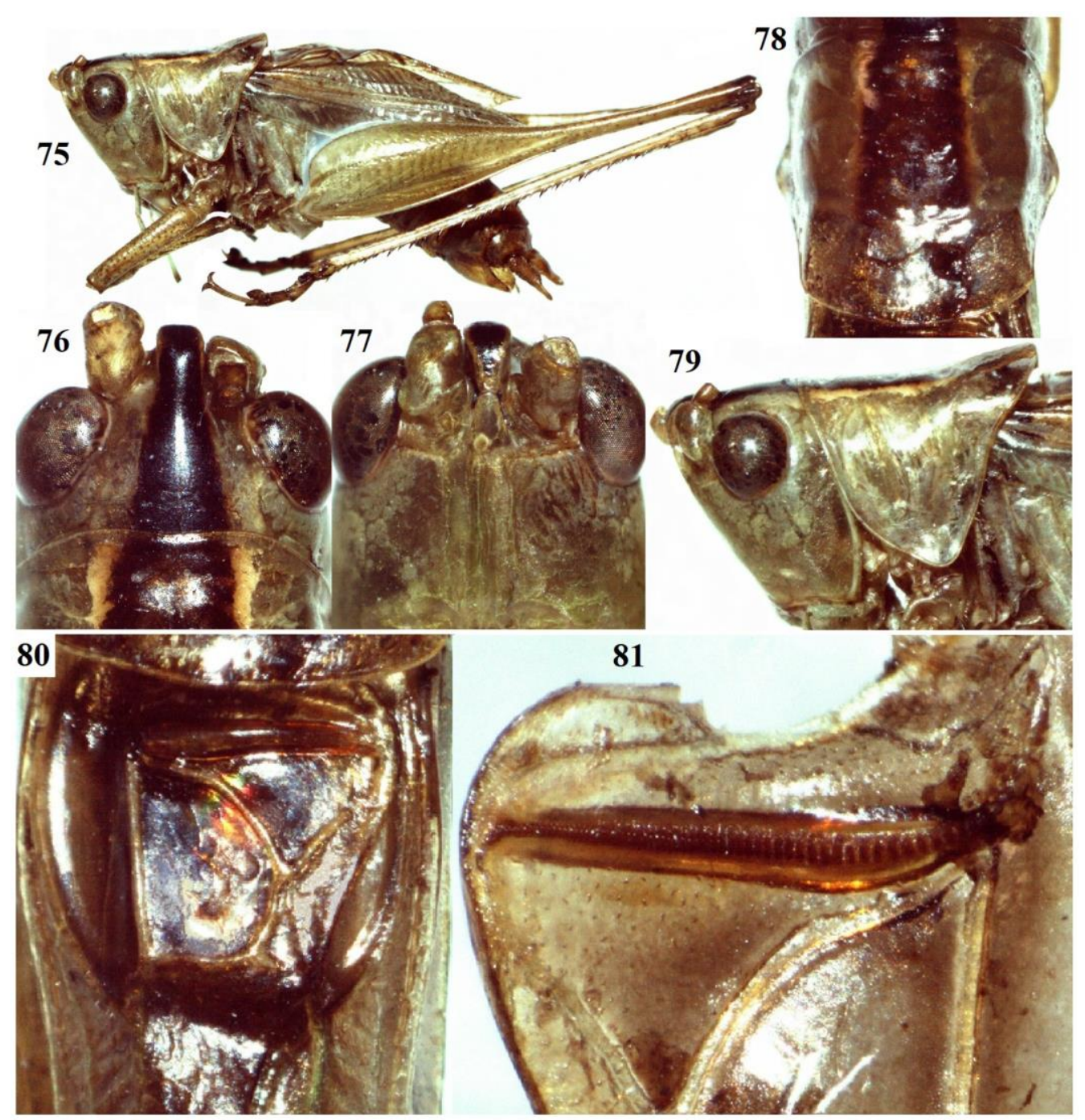

Figuras 75-81. Conocephalus (A.) tepemeh n. sp. Macho, 75) habitus. 76) cabeza y fastigio del vértex, vista dorsal. 77) cabeza y fastigio del vértex, vista frontal. 78) pronoto, vista dorsal. 79) pronoto, vista lateral. 80) aparato estridulador. 81) peine estridulador. 
Hábitat. Conocephalus (Anisoptera) tepemeh n. sp., habita en la Provincia Biogeográfica de la Sierra Madre Oriental, en la región de la Huasteca hidalguense. El clima en el municipio de Huazalingo es cálido, registra una temperatura media anual de $21^{\circ} \mathrm{C}$ y una precipitación media anual de 2,350 $\mathrm{mm}$. El ecosistema en el que vive esta especie es selva mediana, con una gran variedad de plantas entre las que destacan: Bursera simaruba (Burseraceae), Spondias sp. (Anacardiaceae), Cedrela odorata (Meliaceae), Ardisia escallonioides (Primulaceae), Lantana sp. (Verbenaceae) y Pachyrhizus sp. (Fabaceae).

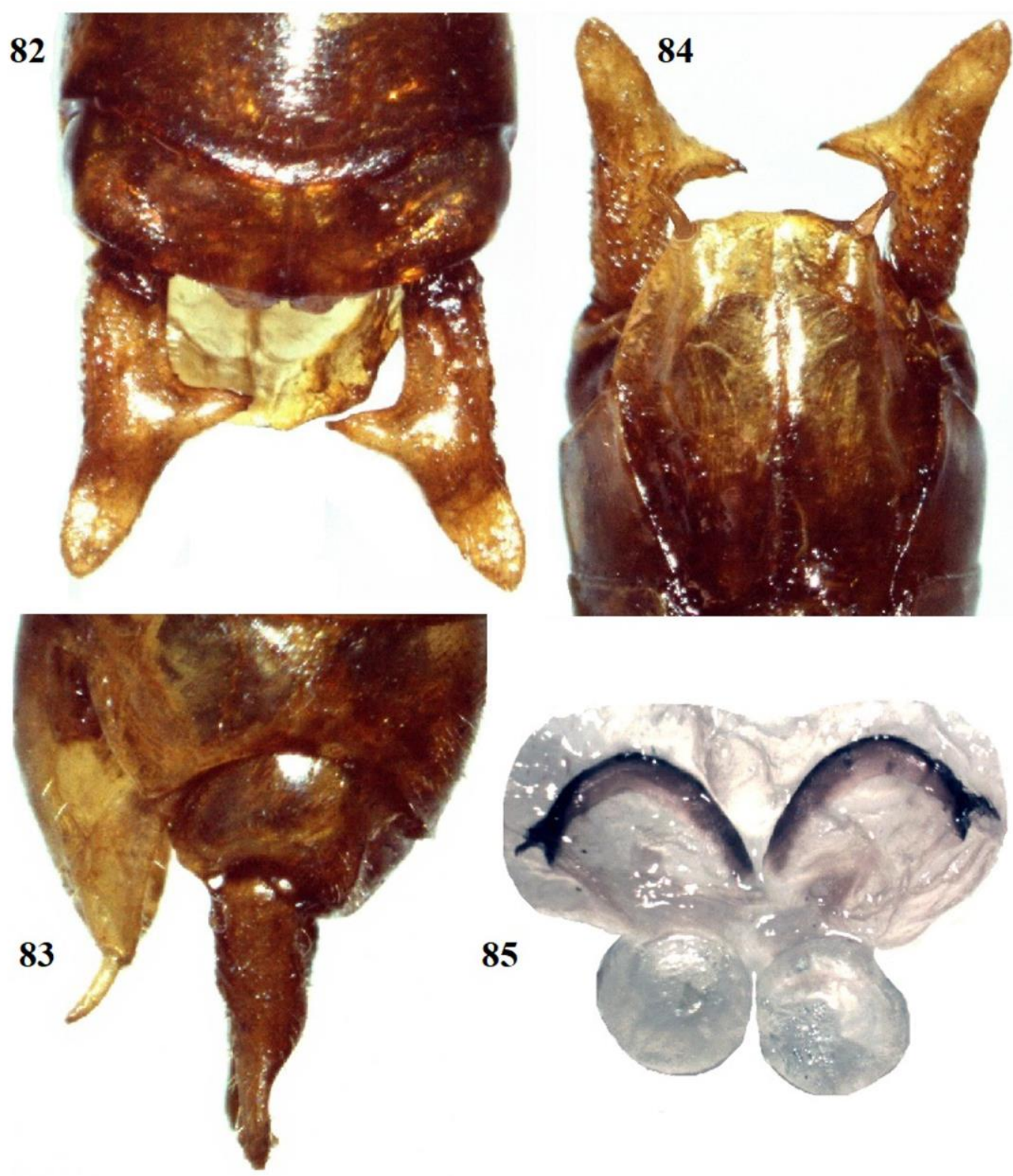

Figuras 82-85. Conocephalus (A.) tepemeh n. sp. Macho, 82) cercos vista dorsal. 83) cercos vista lateral. 84) plato subgenital, vista ventral. 85) genitalia interna, vesícula eyaculadora (VEY) y titiladores (TS), vista dorsal. 


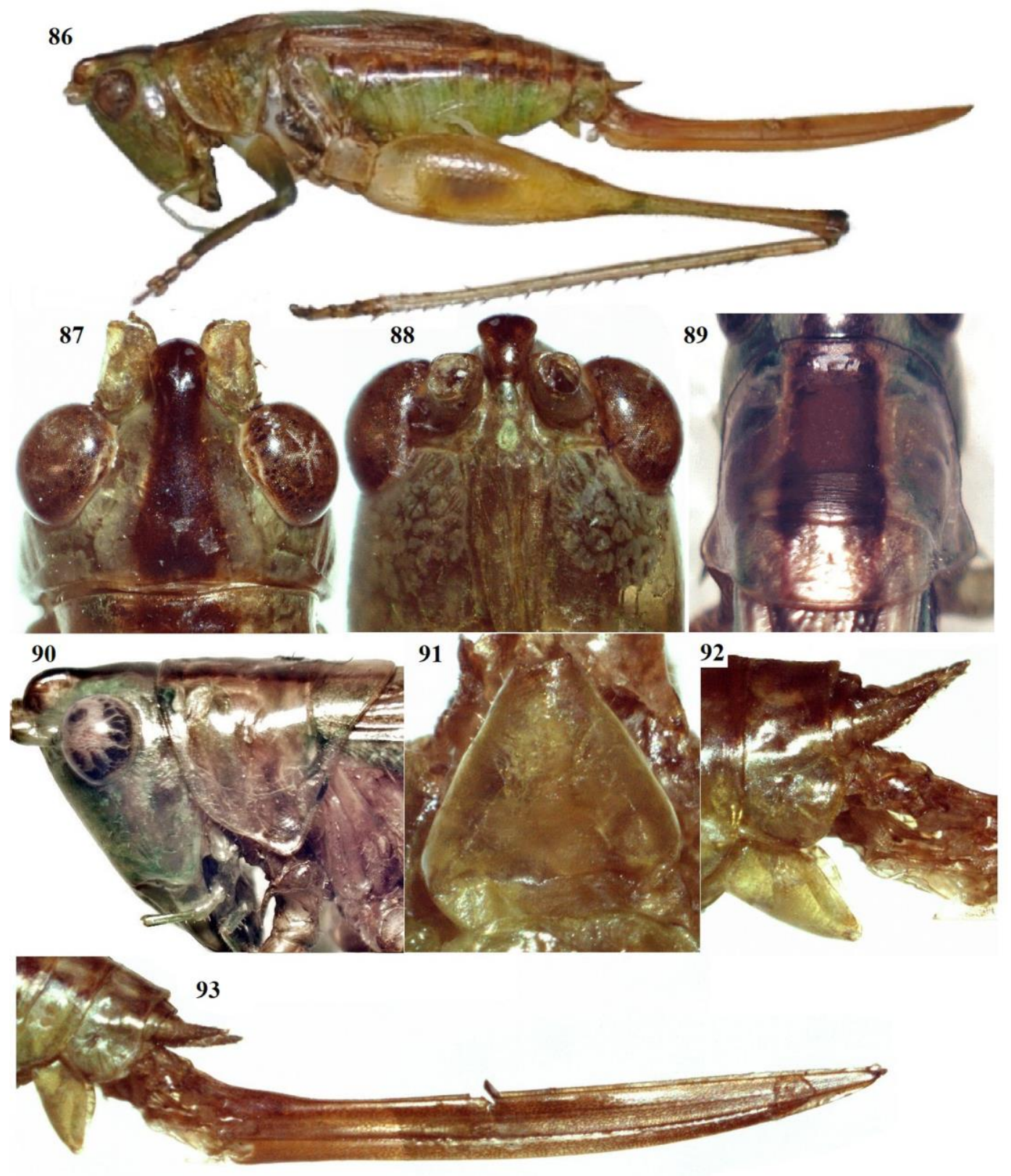

Figuras 86-93. Conocephalus (A.) tepemeh n. sp. Hembra, 86) habitus. 87) cabeza y fastigio del vértex, vista dorsal. 88) cabeza y fastigio del vértex, vista frontal. 89) pronoto, vista dorsal. 90) pronoto, vista lateral. 91) plato subgenital, vista ventral. 92) plato subgenital, vista lateral. 93) ovipositor, vista lateral.

Etimología. El nombre específico "tepemeh" fue asignado en honor a la cultura indígena de la Huasteca hidalguense en el Estado de Hidalgo, México. "Tepemeh" es una palabra en lengua náhuatl que significa "cerro o montaña". Ejemplares de C. tepemeh n. sp., se recolectaron en San Juan, Huazalingo, localidad donde el $90 \%$ de su superficie está constituida por cerros y laderas. 
Señal acústica (Figs. 94-95). Se analizaron 11 min del canto de llamado de C. tepemeh n. sp. Éste se produce en forma continua, durante el día y la noche, con un ISMa de tamaño variable (7.18 \pm $4.74 \mathrm{~s} ; 2.66-18.43 ; n=23$ ). Los equemas o grupos de tren de pulsaciones (GTP) se emiten en forma individual, o con frecuencia simulan grupos de dos, tres o hasta cuatro equemas, cuando éstos se emiten en grupo, el ISMa entre el siguiente equema o grupo de equemas es más largo, lo que explica la variación en la duración del ISMa. Cada equema está compuesto de cero a tres sílabas individuales al inicio, usualmente una o ninguna, seguidas por un tren de sílabas continuas (34.7 \pm 10.0 silabas; $14-60 ; n=26)$. Los equemas tienen una duración de $3.5 \pm 1.0 \mathrm{~s}(1.75-5.55 ; n=26)$ (incluye sílabas individuales y tren de sílabas continuas). Cada sílaba individual, al inicio del equema, tiene una duración de $135 \pm 7$ ms (101-163; $n=28)$; el tren de sílabas continuas dura $2.87 \pm 0.84 \mathrm{~s}(1.15-5.01 ; n=26)$. El espectro de frecuencia está en el rango de 10 a $>56 \mathrm{kHz}$ (Fig. $95)$, con una frecuencia pico (fi) de $20-30 \mathrm{kHz}$. La tasa de repetición es de $5.4 \pm 1.2 \mathrm{E} / \mathrm{min}$.
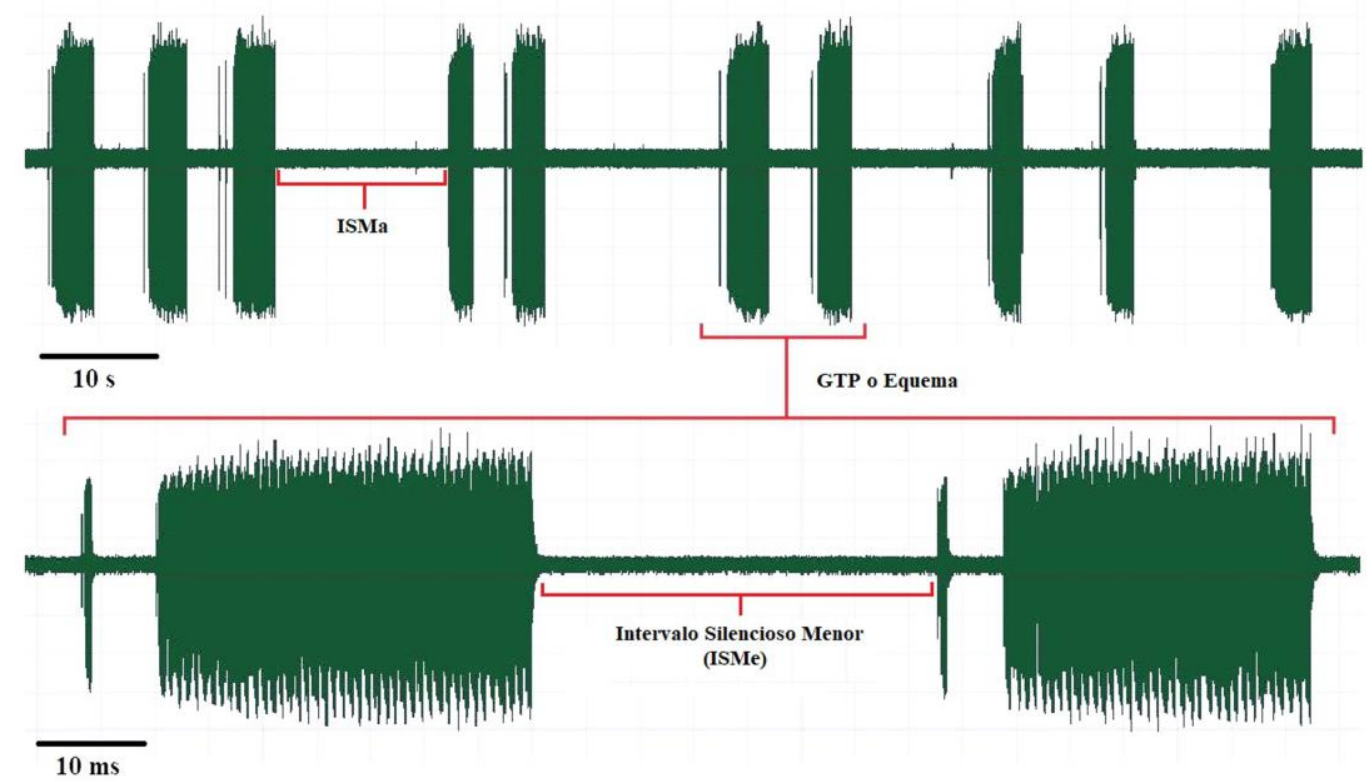

Figura 94. Oscilograma de la señal acústica de llamado de un macho de Conocephalus (A.) tepemeh n. sp. de Huazalingo, Hidalgo, México.

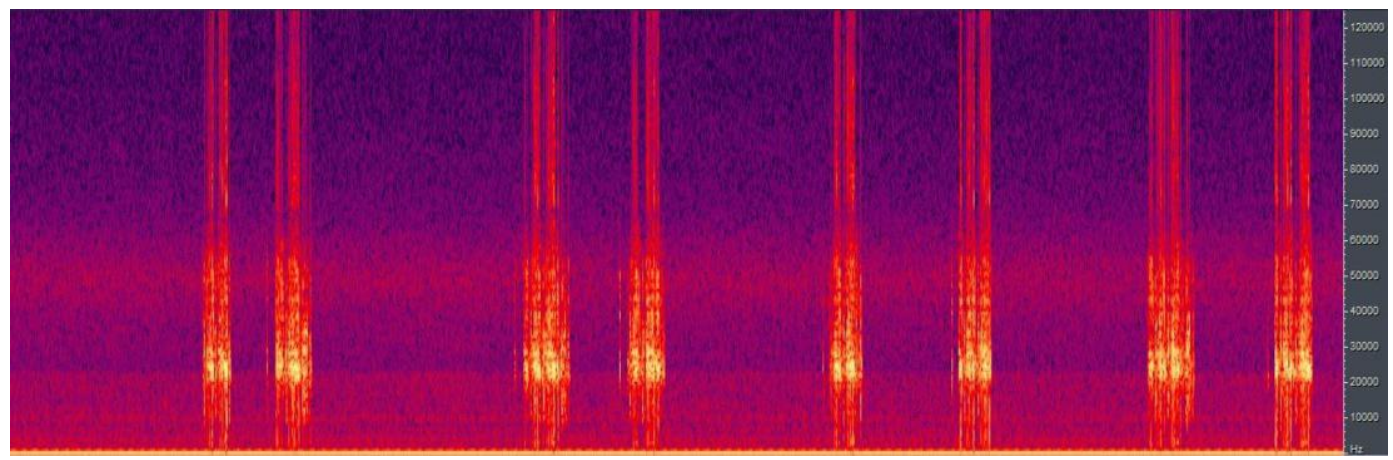

Figura 95. Sonograma y espectro de frecuencia en la señal acústica de llamado de un macho de Conocephalus ( $A$.) tepemeh n. sp. de Huazalingo, Hidalgo, México. 


\section{DISCUSIÓN}

Aunque los géneros Conocephalus Thunberg, 1815 y Orchelimum Serville, 1838-1839, no están bien delimitados (Naskrecki, 2000), las especies que aquí se describen, C. jaliscienses n. sp., C. tempoalensis n. sp., y C. tepemeh n. sp., se asignan al género Conocephalus considerando los caracteres que se reportan de utilidad para separar estos taxones: a) apariencia general del cuerpo, tamaño pequeño, alargados y menos robusto que los miembros del género Orchelimum; b) cercos de los machos no carinados dorsalmente, ni excavados en o cerca de la base del diente medio, ocasionalmente carinados e invariablemente excavados en o cerca de la base del diente medio en Orchelimum; c) el plato subgenital en machos, generalmente truncado distalmente o con emarginación triangular, emarginado en forma de " $\mathrm{V}$ " o " $\mathrm{U}$ " en miembros del género Orchelimum; d) la frecuencia pico (fi) en la señal acústica, la cual se reporta en el rango de $30 \mathrm{kHz}$ o mayor en Conocephalus, mientras que en los miembros del género Orchelimum la fi pico está en el rango de 18 kHz (Rehn \& Hebard 2015a; b; c). Ambos linajes, Conocephalus y Orchelimum, deben ser revisados para establecer con claridad su afinidad a través del análisis de los rasgos morfológicos, bioacústicos, conductuales y moleculares que los distinguen.

Las tres especies que se describen son endémicas para México. Es posible que conforme se avance en el estudio de este género, ejemplares de estos taxones puedan recolectarse en otras localidades, como ocurre con C. ictus y C. magdalenae, que son de amplia distribución (Naskrecki, 2000; Barrientos-Lozano et al., 2015; Cedillo-Salinas et al., 2018). Conocephalus jaliscienses n. sp., se recolectó en el occidente de México, antes de Lagos de Moreno, Jalisco, provincia biogeográfica del Eje Neovolcánico, Subprovincia Altos de Jalisco; C. tempoalensis n. sp., en Tempoal de Sánchez, Veracruz, provincia fisiográfica de la Llanura Costera del Golfo Norte y C. tepemeh n. sp., en Huazalingo, Hidalgo, provincia biogeográfica de la Sierra Madre Oriental, Subprovincia del Carso Huasteco; las dos últimas Subprovincias y especies corresponden a la región Huasteca mexicana. Estos nuevos taxones ocurren simpátricamente con otras especies de los géneros Conocephalus y Orchelimum que se presentan en el territorio mexicano, p. ej., C. ictus, C. magdalenae y Orchelimum (Metarhoptrum) unispina (Saussure \& Pictet, 1893-1899). Sin embargo, se pueden diferenciar mediante caracteres morfológicos, genitalia interna y la señal acústica de llamado que emiten los machos (Cuadros $1 ; 2$ ). Conocephalus jaliscienses n. sp., puede llegar a confundirse con O. (M.) unispina, con la que ocurre simpátricamente (Cigliano et al., 2021). No obstante, puede separarse fácilmente de la última especie mediante los cercos de los machos, que no están carinados dorsalmente ni presentan excavación próxima a la base del diente medio en la cara interna; caracteres presentes en $O$. (M.) unispina (ver http://orthoptera.speciesfile.org/Common/basic/Taxa.aspx?TaxonNameID=1133 650). También pueden separarse por la frecuencia pico $(f i)$ de la señal acústica, que es de $26-36 \mathrm{kHz}$ en $C$. jaliscienses n. sp. vs. $14 \mathrm{kHz}$ en O. (M.) unispina. 
Cuadro 1. Comparación de caracteres morfológicos de la genitalia externa e interna en taxones del género Conocephalus. Se señalan en negrita los taxones descritos en este trabajo.

\begin{tabular}{|c|c|c|c|}
\hline & \multicolumn{2}{|l|}{ Machos } & \multirow{2}{*}{$\begin{array}{l}\text { Hembras } \\
\text { Ovipositor }\end{array}$} \\
\hline & Cercos & Genitalia interna & \\
\hline $\begin{array}{l}\text { Conocephalus (A.) } \\
\text { jaliscienses n. sp. }\end{array}$ & $\begin{array}{l}\text { Figs. 8-10. Subcilíndricos } \\
\text { proximalmente, ensanchados } \\
\text { antes de la porción media, } \\
\text { donde se origina -en cada } \\
\text { cerco- un diente curvo } \\
\text { hacia dentro con una espina } \\
\text { distal de color negro; el } \\
\text { diente es más robusto, más } \\
\text { corto, distalmente menos } \\
\text { agudo y proximal y } \\
\text { distalmente menos curvo } \\
\text { que en C. magdalenae. En } \\
\text { general, los cercos son } \\
\text { menos robustos que en C. } \\
\text { magdalenae, apicalmente } \\
\text { son más angostos, } \\
\text { ligeramente comprimidos y } \\
\text { el ápice es redondo y } \\
\text { divergente. }\end{array}$ & $\begin{array}{l}\text { Vesículas eyaculadoras } \\
\text { (Fig. 11) subcirculares, } \\
\text { más grandes que en } C \text {. } \\
\text { magdalenae. Titiladores } \\
\text { gruesos, de color negro, } \\
\text { ápice fuertemente } \\
\text { bifurcado, más } \\
\text { producido que en } C \text {. } \\
\text { magdalenae. }\end{array}$ & N.D \\
\hline C. magdalenae & $\begin{array}{l}\text { Figs. } 23-24 \text {. Subcilíndricos } \\
\text { proximalmente, ensanchados } \\
\text { antes de la porción media, } \\
\text { donde se origina -en cada } \\
\text { cerco- un diente muy curvo } \\
\text { hacia dentro con una espina } \\
\text { distal aguda de color negro. } \\
\text { Los cercos son más robustos } \\
\text { que en C. jaliscienses n. sp. } \\
\text { Apicalmente más anchos } \\
\text { que en C. jaliscienses n. sp., } \\
\text { ligeramente comprimidos, el } \\
\text { ápice es redondo y recto. }\end{array}$ & $\begin{array}{l}\text { Vesículas eyaculadoras } \\
\text { (Fig. 26) subcirculares, } \\
\text { infladas, más pequeñas } \\
\text { que en C. jaliscienses n. } \\
\text { sp. Titiladores finos, de } \\
\text { color negro, ápice } \\
\text { bifurcado. }\end{array}$ & $\begin{array}{l}\text { Ovipositor corto casi } \\
\text { recto, un poco más } \\
\text { delgado } \\
\text { proximalmente, luego } \\
\text { se ensancha } \\
\text { moderadamente, } \\
\text { sobrepasa } \\
\text { ligeramente los } \\
\text { fémures posteriores. } \\
\text { Longitud: } 10.0 \mathrm{~mm} \text {. }\end{array}$ \\
\hline $\begin{array}{l}\text { Conocephalus (A.) } \\
\text { tempoalensis } \mathrm{n} . \\
\text { sp. }\end{array}$ & $\begin{array}{l}\text { Figs. 37-39. Subcilíndricos en } \\
\text { la porción proximal, } \\
\text { ensanchados medialmente } \\
\text { donde se origina el diente } \\
\text { que es ancho en la base, } \\
\text { moderadamente curvo hacia } \\
\text { dentro, se adelgaza } \\
\text { gradualmente y termina en } \\
\text { una pequeña espina de color } \\
\text { marrón. En general, los } \\
\text { cercos son menos robustos y } \\
\text { más cortos que en C. ictus; a }\end{array}$ & $\begin{array}{l}\text { Vesículas eyaculadoras } \\
\text { (Fig. 40) subcirculares, de } \\
\text { mayor tamaño que en } C \text {. } \\
\text { ictus. Titiladores } \\
\text { robustos, ligeramente } \\
\text { más curvos que en } C \text {. } \\
\text { ictus, de color negro con } \\
\text { ápice bifurcado, la } \\
\text { proyección superior } \\
\text { ligeramente más larga } \\
\text { que la inferior. }\end{array}$ & $\begin{array}{l}\text { Ovipositor (Fig. 48) } \\
\text { casi recto, sobrepasa } \\
\text { el ápice de los } \\
\text { fémures posteriores. } \\
\text { Longitud: } 12.5 \mathrm{~mm} \text {. }\end{array}$ \\
\hline
\end{tabular}




\begin{tabular}{|c|c|c|c|}
\hline & \multicolumn{2}{|l|}{ Machos } & \multirow{2}{*}{$\begin{array}{l}\text { Hembras } \\
\text { Ovipositor }\end{array}$} \\
\hline & Cercos & Genitalia interna & \\
\hline & $\begin{array}{l}\text { partir de la porción media, } \\
\text { donde se observa una leve } \\
\text { protuberancia, se adelgazan } \\
\text { gradualmente y son más } \\
\text { angostos que en C. ictus, el } \\
\text { ápice es amplio y redondo. }\end{array}$ & & \\
\hline C. ictus & $\begin{array}{l}\text { Figs. 59-61. En general, } \\
\text { mucho más robustos y } \\
\text { grandes que en C. } \\
\text { tempoalensis n. sp. } \\
\text { Subcilíndricos en la porción } \\
\text { proximal, ensanchados } \\
\text { medialmente donde se } \\
\text { origina el diente que es } \\
\text { ancho en la base, curvo hacia } \\
\text { dentro, se adelgaza } \\
\text { gradualmente y termina en } \\
\text { una espina de color marrón } \\
\text { curva hacia dentro; a partir } \\
\text { de la porción media, donde } \\
\text { se observa una leve } \\
\text { protuberancia, se adelgazan } \\
\text { gradualmente- pero son más } \\
\text { anchos que en C. } \\
\text { tempoalensis n. sp.; el ápice } \\
\text { es más amplio y redondo. }\end{array}$ & $\begin{array}{l}\text { Vesículas eyaculadoras } \\
\text { (Fig. 62) subcirculares, } \\
\text { pequeñas. Titiladores } \\
\text { finos, de color negro, con } \\
\text { ápice bifurcado; la } \\
\text { proyección superior } \\
\text { ligeramente más larga } \\
\text { que la inferior. }\end{array}$ & $\begin{array}{l}\text { Ovipositor (Fig. } 71 \text { ) } \\
\text { color marrón, en } \\
\text { forma de sable } \\
\text { ligeramente curvo } \\
\text { hacia arriba. Longitud: } \\
13.1 \mathrm{~mm} \text {. }\end{array}$ \\
\hline $\begin{array}{l}\text { Conocephalus (A.) } \\
\text { tepemeh n. sp. }\end{array}$ & $\begin{array}{l}\text { Figs. 82-84. En general, } \\
\text { menos robustos y más } \\
\text { cortos que en C. ictus, } \\
\text { distalmente espatulados y } \\
\text { más anchos. La } \\
\text { protuberancia en la porción } \\
\text { media es más prominente; } \\
\text { diente interno mediano, } \\
\text { subtriangular, amplio en la } \\
\text { base, el ápice termina en una } \\
\text { uña color negro, aguda y } \\
\text { ligeramente curva hacia } \\
\text { dentro; el diente en cada } \\
\text { cerco se observa más } \\
\text { prominente que en C. ictus. }\end{array}$ & $\begin{array}{l}\text { Vesículas eyaculadoras } \\
\text { (Fig. 85) subcirculares, de } \\
\text { mayor tamaño que en } C \text {. } \\
\text { ictus. Titiladores finos, } \\
\text { más largos y ligeramente } \\
\text { más curvos que en C. } \\
\text { ictus, de color negro con } \\
\text { el ápice bifurcado y más } \\
\text { robusto. }\end{array}$ & $\begin{array}{l}\text { Ovipositor (Fig. 93) } \\
\text { color marrón, en } \\
\text { forma de sable, } \\
\text { margen superior } \\
\text { recto, margen inferior } \\
\text { ligeramente curvo. } \\
\text { Longitud: } 11.2 \mathrm{~mm} \text {. }\end{array}$ \\
\hline
\end{tabular}

N.D. No Disponible.

Fuente: Información propia. 
Cuadro 2. Comparación de caracteres morfológicos y de la señal acústica en taxones del género Conocephalus. Se señalan en negrita los taxones descritos en este trabajo.

\begin{tabular}{|c|c|c|c|c|c|}
\hline Taxón & $\begin{array}{l}\text { Longitud } \\
\text { del } \\
\text { cuerpo } \\
(\mathrm{mm})\end{array}$ & $\begin{array}{l}\text { Longitud } \\
\text { peine } \\
\text { estridulador } \\
(\mathbf{m m})\end{array}$ & $\begin{array}{l}\text { Número de } \\
\text { dientes en } \\
\text { peine } \\
\text { estridulador }\end{array}$ & $\begin{array}{l}\text { Frecuencia } \\
\text { pico (fi) en } \\
\text { señal } \\
\text { acústica } \\
(\mathrm{kHz})\end{array}$ & $\begin{array}{l}\text { Tasa de } \\
\text { repetición } \\
\text { (equemas/min) }\end{array}$ \\
\hline C. jaliscienses n. sp. & 22.6 & 8.0 & 39 & $26-36$ & $34 \pm 3.83$ \\
\hline C. magdalenae & 22.1 & $5.8-6.3$ & $47-54$ & $20-30$ & $57-71$ \\
\hline $\begin{array}{l}\text { C. tempoalensis n. } \\
\text { sp. }\end{array}$ & 18.2 & 9.0 & 55 & $22-34$ & $6.6 \pm 1.2$ \\
\hline C. ictus & 18.0 & 5.2 & 65 & $20-30$ & $25 \pm 7.2$ \\
\hline C. tepemeh n. sp. & 21.5 & 8.1 & 59 & $20-30$ & $5.4 \pm 1.2$ \\
\hline
\end{tabular}

Fuente: Información propia.

AgRAdeCImientos. Al Consejo Nacional de Ciencia y Tecnología (CONACYT) por el apoyo brindado a través del Programa Nacional de Becas a LBCS (Beca de Doctorado No. 717236); así como por el apoyo económico a través del proyecto CONACYT/CB/2013/0219979. Al Tecnológico Nacional de México-Instituto Tecnológico de $\mathrm{Cd}$. Victoria, por el apoyo proporcionado para realizar el trabajo de campo.

\section{LITERATURA CITADA}

Barrientos-Lozano, L., Rocha-Sánchez, A. Y., Buzzetti, F. M., Almaguer-Sierra, P., MoraRavelo, S. G. (2015) Señal acústica en dos poblaciones alopátricas de Conocephalus (Xiphidion) ictus (Scudder, 1875) (Orthoptera: Tettigoniidae). Entomología Mexicana, 2, 540546. Disponible en: http://www.entomologia.socmexent.org/revista/2018/EC/EC\%20218224.pdf (consultado: 12 enero 2021).

Bolívar, I. (1877) Sinopsis de los ortópteros de España y Portugal. Pp: 249-358. En: Anales de la Sociedad Española de Historia Natural. Tomo sexto. Disponible en: https://bibdigital.rjb.csic.es/records/item/10488-redirection (consultado: 04 enero 2021)

Buzzetti, F. M., Barrientos-Lozano, L. (2011) Bioacoustics of some Mexican Orthoptera (Insecta: Orthoptera: Ensifera, Caelifera). Bioacoustics, 20, 193-213.

http://doi.org/10.1080/09524622.2011.9753643

Cedillo-Salinas, L. B., Barrientos-Lozano, L., Rocha-Sánchez, A. Y., Almaguer-Sierra, P., Correa-Sandoval, A. (2017) Revisión de Conocephalus Thunberg (Orthoptera) depositados en la colección de ortópteros del Instituto Tecnológico de Cd. Victoria, Tamaulipas, México. Entomología Mexicana, 4, 738-743. Disponible en: http://www.socmexent.org/entomologia/revista/2017/SM/EM0972017_738-743.pdf (consultado: 06 enero 2021).

Cedillo-Salinas, L. B., Barrientos-Lozano, L., Rocha-Sánchez, A. Y., Almaguer-Sierra, P., Correa-Sandoval, A. (2018) Comportamiento acústico de Conocephalus (Anisoptera) magdalenae Naskrecki, 2000 (Orthoptera: Tettigoniidae). Entomología Mexicana, 5, 218- 
224. Disponible en: http://www.entomologia.socmexent.org/revista/2018/EC/EC\%20218224.pdf (consultado: 10 enero 2021).

Cedillo-Salinas, L. B, Barrientos-Lozano, L., Rocha-Sánchez, A. Y., Almaguer-Sierra, P., Correa-Sandoval, A. (2019) Genitalia interna de cuatro especies del género Conocephalus Thunberg, 1815 (Orthoptera: Tettigoniidae). Entomología Mexicana, 6, 649-654. Disponible en: $\quad$ http://www.entomologia.socmexent.org/revista/2019/SM/SM\%20649-654.pdf (consultado: 04 enero 2021).

Chamorro-Rengifo, J., Lopes-Andrade, C. (2014) The phallus in Tettigoniidae (Insecta: Orthoptera: Ensifera): Revision of morphology and terminology, and discussion on its taxonomic importance and evolution. Zootaxa, 3815 (2), 151-199.

https://doi.org/10.11646/zootaxa.3815.2.1

Cigliano, M. M., Braun, H., Eades, D. C., Otte, D. (2021) Orthoptera Species File. Version 5.0/5.0. Disponible en: http://orthoptera.speciesfile.org/Common/editTaxon/SearchForTaxon.aspx (consultado: 11 enero 2021).

Dutta, R., Tregenza, T., Balakrishnan, R. (2017) Reproductive isolation in the acoustically divergent groups of tettigoniid, Mecopoda elongata. PLOS ONE, 12 (11), e0188843. https://doi.org/10.1371/journal.pone.0188843

Fontana, P., Mariño-Pérez, R., Woller, D. A. (2013) Studies in Mexican Tettigoniidae: A new genus of Copiphorini and the first description of male Conocephalus (Aphauropus) leptopterus Rehn and Hebard and the female of Insara acutitegmina Fontana, Buzzetti, Mariño-Pérez \& García García. Zootaxa, $3737 \quad$ (4), 429-453. http://doi.org/10.11646/zootaxa.3737.4.6

lorgu, I. Ş. (2012) Acoustic analysis reveals a new cryptic bush-cricket in the Carpathian Mountains (Orthoptera, Phaneropteridae). ZooKeys, 254, 1-22. https://doi.org/10.3897/zookeys.254.3892

lorgu, I. Ş, Krištín, A., Szövényi, G., Kaňuch, P., Jarčuška, B., Sahlean, C. T., lorgu, E. I., Orci, K. M. (2017) Distinctive male-female acoustic duetting supports the specific status of Isophya pratensis, a West-Carpathian endemic bush-cricket (Insecta: Orthoptera: Tettigoniidae: Phaneropterinae). Bioacoustics, 27 (1), 43-56. https://doi.org/10.1080/09524622.2016.1272005

Morris, G. K., Walker, T. J. (1976) Calling songs of Orchelimum meadow katydids (Tettigoniidae). Mechanism, terminology, and geographic distribution. Canadian Entomologist, 108 (8), 785-800. http://doi.org/10.4039/Ent108785-8

Morris, G. K. (2020) Imagine it as it isn't. Disponible en: http://sites.utm.utoronto.ca/glennmorris/content/about (consultado: 18 diciembre 2020).

Naskrecki, P. (2000) Katydids of Costa Rica. Volume I. Systematics and Bioacoustics of the Coneheaded Katydids (Orthoptera: Tettigoniidae: Conocephalinae (sensu lato)). Orthopterists Society. Philadelphia, Pennsylvania, EE. UU. 164 pp.

Rehn, J. A. G., Hebard, M. (1915a) Studies in American Tettigoniidae (Orthoptera). IV. A synopsis of the species of the genus Orchelimum. Transactions of the American Entomological Society, $61 \quad(1), \quad 11-83 . \quad$ Disponible en: http://reader.library.cornell.edu/docviewer/digital?id=chla5077659_4251_001\#page/14/m ode/1up (consultado: 18 diciembre 2020). 
Rehn, J. A. G., Hebard, M. (1915b) Studies in American Tettigoniidae (Orthoptera). V. A synopsis of the species of the genus Conocephalus (Xiphidium of authors) found in North America North of México. Transactions of the American Entomological Society, 61 (2), 155-224. Disponible

en: http://reader.library.cornell.edu/docviewer/digital?id=chla5077659_4251_002\#page/82/m ode/1up (consultado: 18 diciembre 2020).

Rehn, J. A. G., Hebard, M. (1915c) Studies in American Tettigoniidae (Orthoptera). Vl. A synopsis of the species of the genus Conocephalus found in America south of the southern border of the United States. Transactions of the American Entomological Society, 61 (2), 225-290. Disponible en: http://reader.library.cornell.edu/docviewer/digital?id=chla5077659_4251_002\#page/158/ mode/1up (consultado: 18 diciembre 2020).

Rocha-Sánchez, A. Y., Barrientos-Lozano, L., Zaldívar-Riverón, A., Almaguer-Sierra, P. (2016) Importancia de la genitalia en la delimitación de especies de la subfamilia Phaneropterinae (Orthoptera: Tettigoniidae). Entomología Mexicana, 3, 943-949. Disponible en: http://www.socmexent.org/entomologia/revista/2016/SM/Em\%20943-949.pdf (consultado: 12 enero 2021).

Saussure De, H., Zehntner, L., Pictet, A. (1893-1899) Insecta, Orthoptera. Biología CentraliAmericana. Volume I. [Published by R. H. Porter. London], 487 pp. Disponible en: https://www.sil.si.edu/DigitalCollections/bca/navigation/bca_20_01_00/bca_20_01_00selec t.cfm (consultado: 12 enero 2021).

Scudder, S. H. (1875) A century of Orthoptera. Proceedings of the Boston Society of Natural History, 17, 454-517. Disponible en: https://www.biodiversitylibrary.org/item/130650\#page/473/mode/1up (consultado: 20 diciembre 2020).

Serville, M. A. (1838-1839) Histoire Naturelle des Insectes Orthoptères. Librairie Enciclopédique de Roret. Paris, 794 pp. Disponible en: https://www.biodiversitylibrary.org/item/54314\#page/11/mode/1upp (consultado: 12 diciembre 2020).

Simmons, L. W., García-González, F. (2011) Experimental coevolution of male and female genital morphology. Nature Communications, 2, 374. http://doi.org/10.1038/ncomms1379

Thunberg, C. P. (1815) Hemiterorum maxillosorum general illustrata. Plurimisque novis speciebus ditata ac descripta. Mémoires de L'Académie Impériale des Sciences de St. Pétersbourg, 5, 211-301. Disponible en: https://books.google.com.mx/books?id=5woZAAAAYAAJ\&printsec=frontcover\&hl=es\&s ource=gbs_ge_summary_r\&cad=0\#v=onepage \&q\&f=false (consultado: 15 diciembre 2020).

van Haren, M. M., Rönn, J. L., Schilthuizen, M., Arnqvist, G. (2017) Postmating sexual selection and the enigmatic jawed genitalia of Callosobruchus subinnotatus. The Company of Biologists Ltd. Biology, 6, 1008-1012.

http://doi.org/10.1242/bio.025684 
Walker, T. J., Forrest, T. G., Spooner, J. D. (2003) The rotundifolia complex of the genus Amblycorypha (Orthoptera: Tettigoniidae): songs reveal new species. Annals of the Entomological Society of America, 96 (4), 433-447. https://doi.org/10.1603/0013-8746(2003)096[0433:TRCOTG]2.0.CO;2

Walker, T. J. (2019) Singing Insects of North America. Conocephalinae. Disponible en: https://entnemdept.ifas.ufl.edu/walker/buzz/s220a.htm (consultado: 11 septiembre 2020).

Wulff, N., Lehmann, G. (2014) Manipulation of internal genitalia in a bushcricket (Orthoptera: Ensifera: Tettigoniidae): anchors or stimulatory devices. Mitteilungen der Deutschen Gesellschaft für allgemeine und angewandte Entomologie, 19, 169-172. Disponible en: https://www.researchgate.net/publication/267853772 (consultado: 11 septiembre 2020). 